\title{
Buccolingual and Mesiodistal Dimensions of the Permanent Teeth, Their Diagnostic Value for Sex Identification, and Bolton Indices
}

\author{
Vahid Rakhshan $\mathbb{D}^{1},{ }^{1}$ Fataneh Ghorbanyjavadpour $\mathbb{D}^{2},{ }^{2}$ and Negin Ashoori $\mathbb{D}^{3}$ \\ ${ }^{1}$ Department of Anatomy, Dental School, Azad University of Medical Sciences, Tehran, Iran \\ ${ }^{2}$ Department of Orthodontics, School of Dentistry, Ahvaz Jundishapur University of Medical Sciences, Ahvaz, Iran \\ ${ }^{3}$ School of Dentistry, Ahvaz Jundishapur University of Medical Sciences, Ahvaz, Iran
}

Correspondence should be addressed to Fataneh Ghorbanyjavadpour; fa.ghorbanyjavad@gmail.com

Received 10 November 2021; Accepted 18 January 2022; Published 10 February 2022

Academic Editor: Nafij Jamayet

Copyright ( 2022 Vahid Rakhshan et al. This is an open access article distributed under the Creative Commons Attribution License, which permits unrestricted use, distribution, and reproduction in any medium, provided the original work is properly cited.

Introduction. We aimed (1) to measure the mesiodistal and buccolingual widths of the permanent dentition in Iranian orthodontic patients, (2) to determine cut-off points for sex identification based on the mesiodistal and buccolingual diameters, and (3) to calculate Bolton indices. Methods. The mesiodistal and buccolingual dimensions of 28 maxillary and mandibular permanent teeth in 331 Iranian nonsyndromic orthodontic patients (dental casts and radiographs) aged 12 to 35 years old with fully erupted permanent dentitions (except the third molars and some sporadic cases of a few teeth missing or excluded) were measured. The anterior, posterior, and overall Bolton ratios were calculated in cases with no missing teeth in the 6-to-6 range. Potentially associated factors (the skeletal Angle classes, crowding, sex, jaws, sides, and age), as well as the value of these measurements for sex determination and cut-off points for sex identification based on these measurements were assessed using receiver-operator characteristic (ROC) curves, analysis of variance (ANOVA), Tukey, unpaired $t$-test, partial and Pearson correlation coefficients, and multiple linear regression $(\alpha=0.05)$. Results. Sex dimorphism was very frequent $(P \leq 0.05$ in 41 out of 56 measurements). Only the buccolingual widths of the maxillary lateral and the mandibular central and lateral differed across the Angle classes (ANOVA/Tukey, $P<0.05)$. Cut-off points were estimated for 38 dental measurements, which were proper for sex identification $(P<0.05)$, with $8(2$ maxillary and 6 mandibular) measurements being highly appropriate (having areas under ROC curves $\geq 64 \%, P<0.05$ ). Both the mandibular canines were the only teeth with all four measurements highly appropriate for this purpose. Controlling for the role of sex, aging was associated negatively with several crown dimensions (the buccolingual widths of the maxillary first and second premolar and mandibular second premolar and first molar; the mesiodistal diameters of the maxillary central, canine, first premolar, and first molar, mandibular central, lateral, first premolar, and first molar, $P \leq$ 0.05 , partial correlation coefficient). There were significant correlations among crown sizes. All the 28 (right/left-averaged) measurements were smaller in microdontia cases $(P \leq 0.002)$. The anterior, posterior, and overall Bolton indices were 78.05 , 105.42, and 91.87, respectively. There were correlations between the overall Bolton ratio with the other two Bolton ratios (Pearson $R=0.696, R=0.740, P<0.0005)$ but not between the anterior and posterior Bolton ratios $(R=0.045, P=0.459)$. The skeletal Angle classes might not be associated with the overall and anterior Bolton ratios (ANOVA, regression, Pearson, $P>$ 0.05). However, the posterior Bolton ratio was smaller in class II cases compared to classes I or III (Tukey, $P \leq 0.045$ ). In the whole sample, there was no sex dimorphism in Bolton ratios ( $t$-test, $P>0.05)$. However, in Angle class II patients, the anterior Bolton ratio was greater in men than in women $(P=0.014)$. Conclusions. Sex dimorphism might be very common in the dentition of Iranians, with aging significantly reducing some measurements. The buccolingual widths of some incisors might differ across the skeletal Angle classes. Mandibular canines are the most appropriate teeth for sex identification. The Angle classes might not be associated with the anterior and overall Bolton ratios; nevertheless, the posterior Bolton ratio might be smaller in class II cases compared to others. In general, sex might not affect Bolton ratios; however, in class II patients, the anterior Bolton ratios might be larger in men. 


\section{Introduction}

An important issue in dentistry is metric dental traits or mesiodistal and buccolingual crown sizes [1]. Tooth sizes are important in orthodontics, prosthodontics, restorative dentistry, anatomy, and even anthropological and forensic studies. One of the functions of orthodontists is to correct problems caused by dental size discrepancies in order to improve the mastication efficiency, the beauty of the face, and the orderliness of the dental arch [2]. Knowing the size of the teeth in populations and individuals is critical for proper diagnosis, planning an appropriate treatment, and predicting the results of orthodontic treatment [2-4]. The buccolingual dimension of the teeth is clinically important as one of the determining factors of the width of the upper and lower jaws, the width of the palate, and the space of the tongue. Therefore, the buccolingual dimensions of the teeth are related to the correct arrangement of the posterior teeth [5]. The mesiodistal dimension of the teeth has crucial orthodontic implications: to obtain an optimal occlusion, the mesiodistal measurements of the mandibular and maxillary teeth should relate to each other $[6,7]$. Considerable intermaxillary mesiodistal size discrepancies-which are not uncommon-disallow aligning the teeth into an optimal occlusion [7-9]. To account for such intermaxillary relationships, Bolton [10] devised the concept of anterior and overall intermaxillary mesiodistal tooth size ratios (Bolton indices). Later, it was shown that Bolton ratios might be ethnic-specific and therefore should be assessed in different populations $[6,7,11]$.

Dental crown dimensions can be used in anthropological studies, evolutionary research, and forensic sciences [3, 12-15]. Gender identification in injured bodies is an essential step and even the first step for forensic purposes [16, 17]. Determining sex through dental traits is a common practice in forensic dentistry and anthropology [18]. The most common measurements used for such purposes are mesiodistal and buccolingual widths which are convenient and reliable [19]. Numerous factors can interfere with tooth size variability, including genetic, epigenetic, or environmental factors [20]. Dental crowns might be larger in men than in women, especially in the case of the canines [13, 21-26]. Therefore, teeth are one of the desirable items for human and sex identification $[24,27,28]$. Dental sizes might also be used to estimate age [29].

Since not many studies have been done on metric dental traits especially large studies or studies in the Iranian population, we aimed to document the metric dental traits (56 mesiodistal and buccolingual crown dimensions of 28 permanent teeth) and then to determine sex dimorphism in each of the dimensions of each permanent tooth. Furthermore, the usefulness of these measurements in identifying the sex was assessed, and the cut-off point for gender determination was estimated. The associations between metric dental traits with the skeletal Angle classification and crowding were examined. Finally, we measured the Bolton intermaxillary mesiodistal tooth size ratios (Bolton indices); we also evaluated the associations between Bolton ratios with the skeletal Angle classes, sex, and age. Besides, we compared the Bolton ratios in this ethnic group with the original ratios measured by Bolton in American Caucasians [10].

\section{Materials and Methods}

This cross-sectional epidemiological study was performed on 662 maxillary and mandibular dental casts of 331 Iranian orthodontic patients attending the Orthodontic Department and two private orthodontic clinics in Ahvaz, Iran.

For data collection, all the available patients' records and their archival radiographs and casts were subsequently checked and approved/rejected until reaching the desired sample size. The inclusion criteria were being Iranian, 12 to 35 years old, and having a full permanent dentition except for the third molars and with no more than 2 extractions. The exclusion criteria were patients with cleft palates or lips or any systemic diseases or syndromes; patients with any history of previous prosthodontic, surgical, or orthodontic treatments; patients without a complete set of permanent teeth (except cases of hypodontia, cases of single excluded teeth, cases of one or two extracted teeth, and also except the third molars); cases with more than two extracted teeth; patients with more than two partially erupted permanent teeth; cases with poor cast quality; and cases without lateral cephalographs and panoramic radiographs. Additionally, single teeth that were not fully erupted or had (visible or a filed history of) dental caries, crown fractures, restorations, or veneers were excluded. Information on age, sex, and type of the skeletal Angle classification was recorded from the patients' files and their cephalographs. Data collection was performed from 2018 to 2020 [30, 31].

The used casts and radiographs were all archival, and thus, no harm was identified with this study. The protocol ethics were approved by the research committee of the university in accordance with the Helsinki Declaration (ethics code: U-98142).

All the used dental casts had been poured with white dental stone for orthodontic use. All the 56 dental buccolingual and mesiodistal dimensions of the 28 teeth were measured by a trained dentist at the quarter level (for each hemimaxilla or hemimandible of each patient separately): a digital caliper at an accuracy of $0.01 \mathrm{~mm}$ was used to measure the buccolingual distance (the largest distance between the buccal and lingual surfaces of the crown perpendicular to the mesiodistal width of that tooth, from the buccal to the lingual height of contours) and mesiodistal dimension (as the maximum distance between the mesial contact point and distal contact point, when the caliper is parallel to the buccal tooth surface); in case the proximal tooth was absent or the tooth was rotated, the anatomically normal contact points of the tooth would be detected by the observer [1, 20]. Microdontia was considered a very small size of a tooth but with a normal shape [32].

Cases with any missing teeth within the tooth range of bimaxillary first 12 teeth (bilateral centrals to the first molars) were identified and excluded. In the remaining 268 patients with no missing teeth in the bimaxillary 6-6 range, the sums of the mesiodistal diameters of the anterior 3 teeth (canineto-canine) were calculated in the maxilla and also in the mandible. The anterior Bolton ratio was calculated as "100 $\times$ the sum of the mesiodistal widths of the 6 mandibular anterior teeth/the sum of the mesiodistal widths of the 6 maxillary anterior teeth" [7-10]. Similarly, in these 268 cases, the sums 
TABle 1: Descriptive statistics and 95\% CIs for the mesiodistal and buccolingual widths $(\mathrm{mm})$ in the right and left sides of the maxilla in males versus females (compared using the $t$-test).

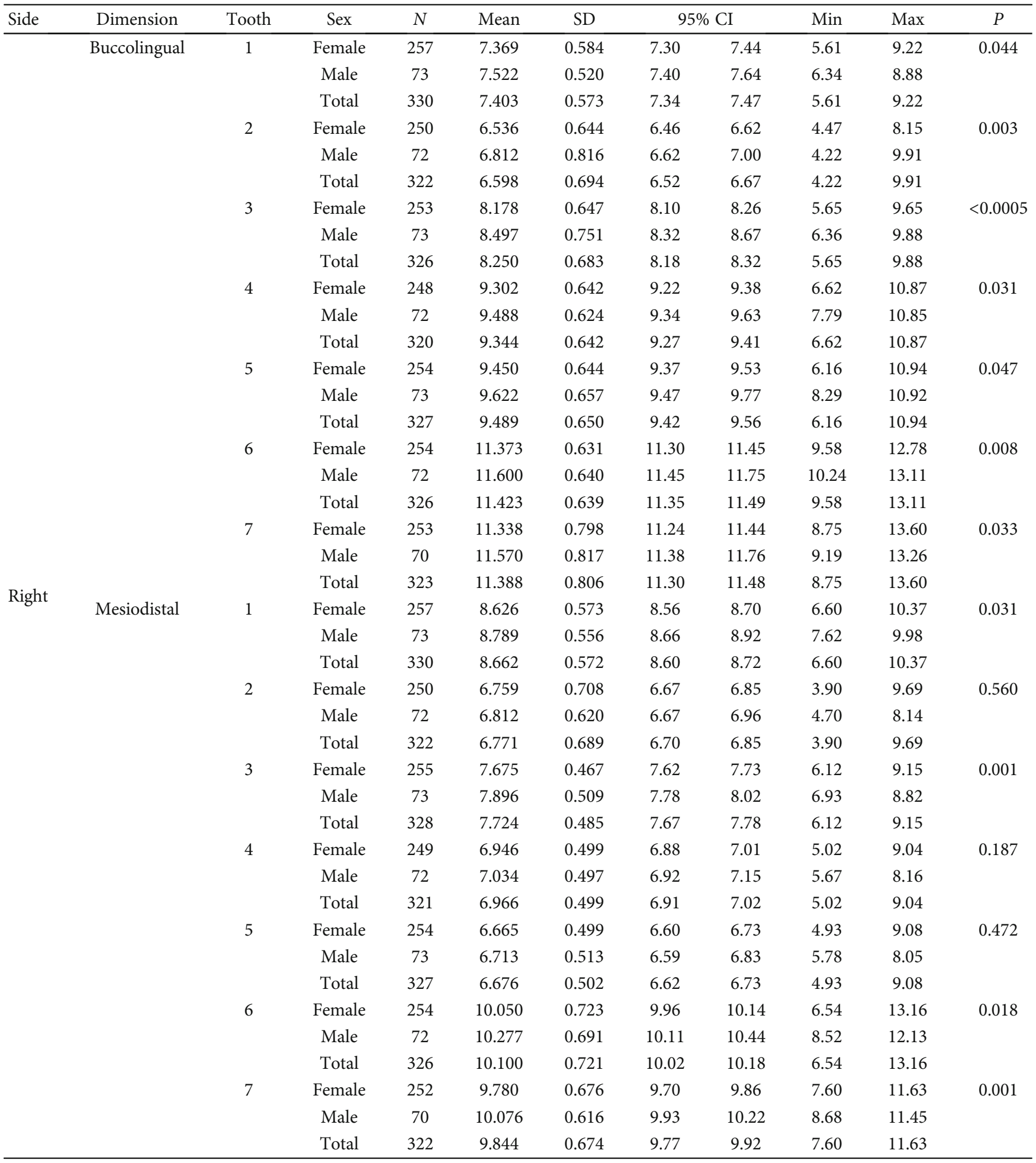


TABLE 1: Continued.

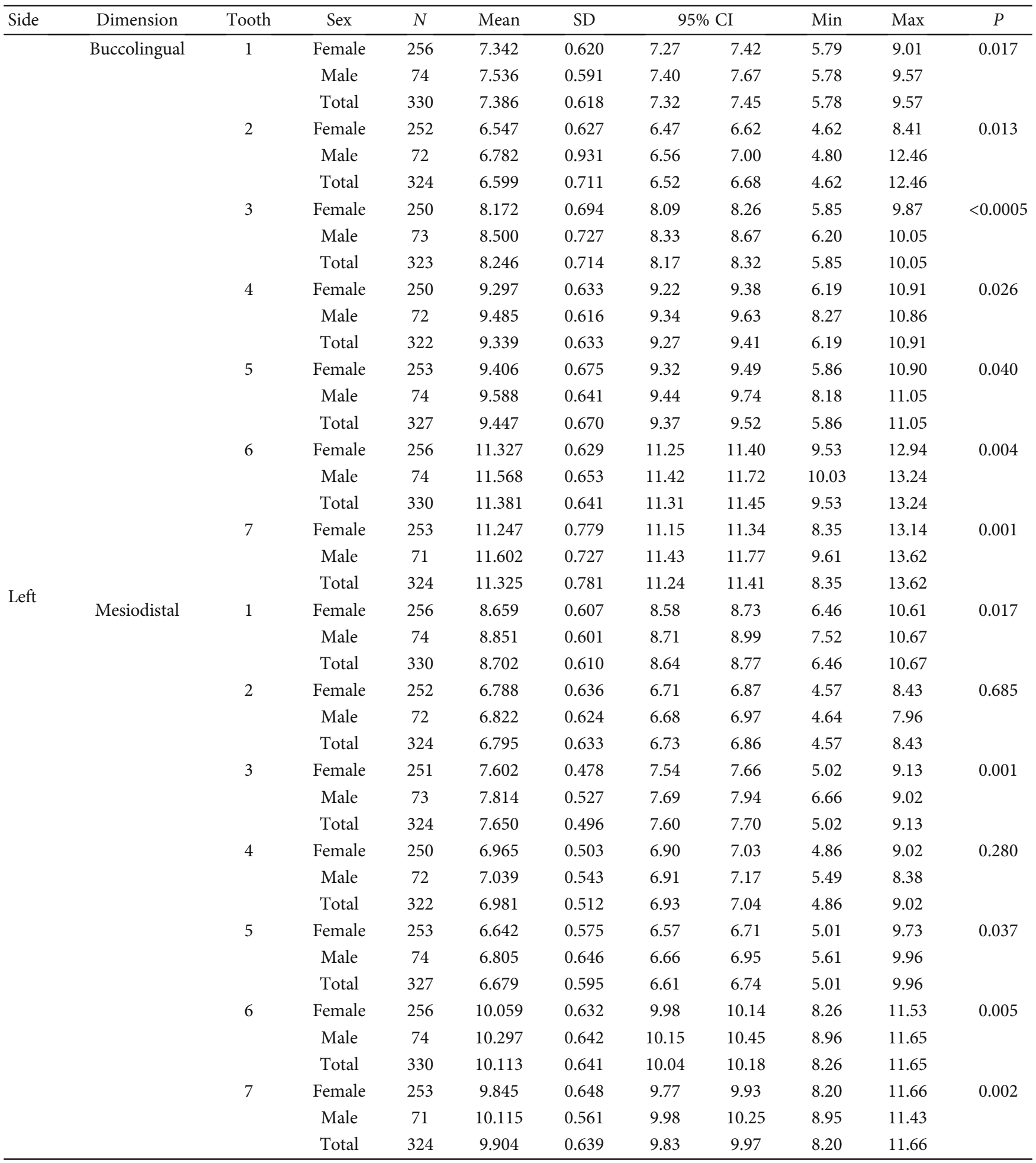

Tooth numbers 1 to 7 denote the most anterior (the central) to the most posterior (the second molar) teeth. SD: standard deviation; CI: confidence interval; Min: minimum; Max: maximum. 
TABle 2: Descriptive statistics and 95\% CIs for crown measurements ( $\mathrm{mm}$ ) in the mandible, compared between the sexes (using the $t$-test).

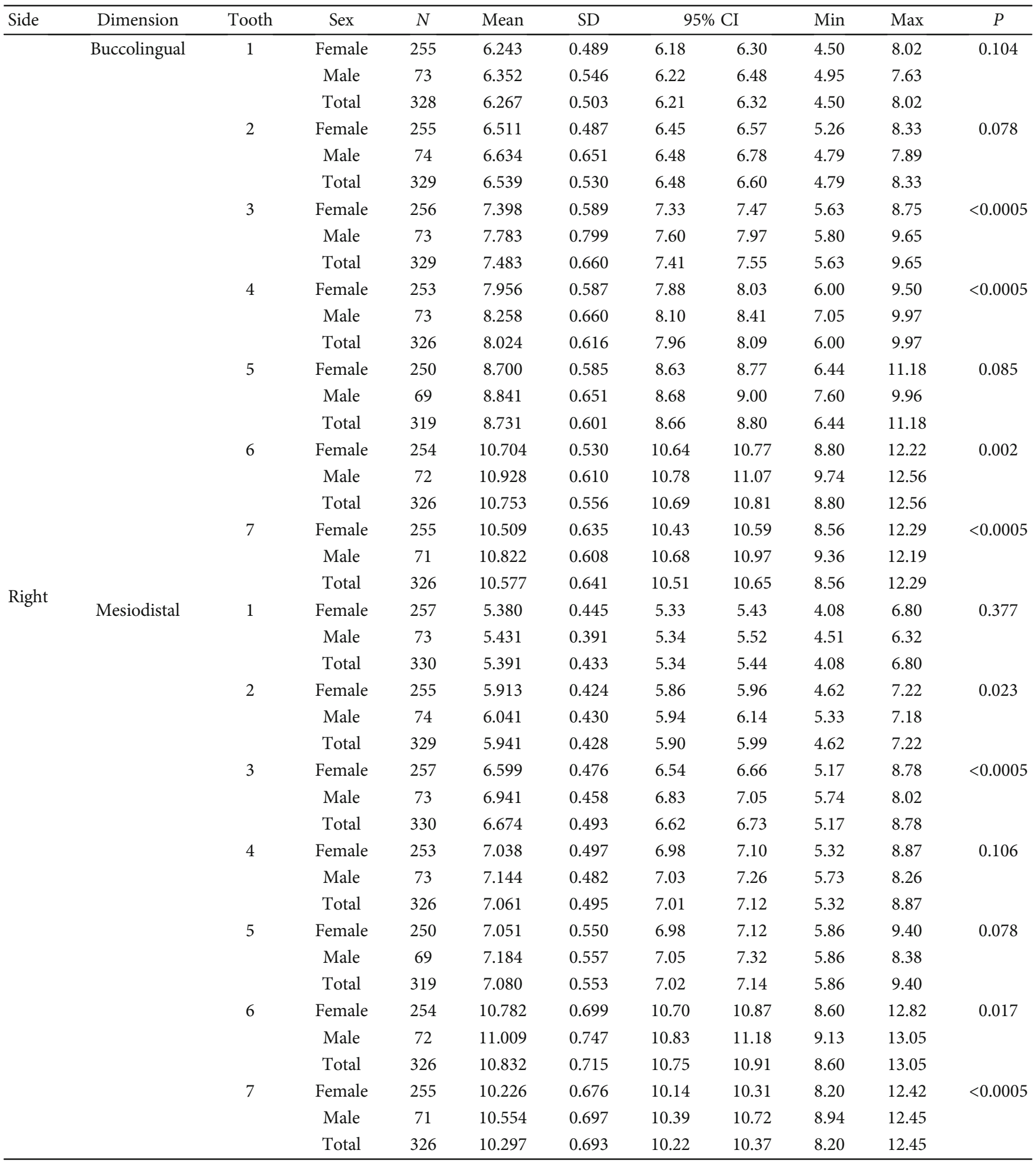


TABLE 2: Continued.

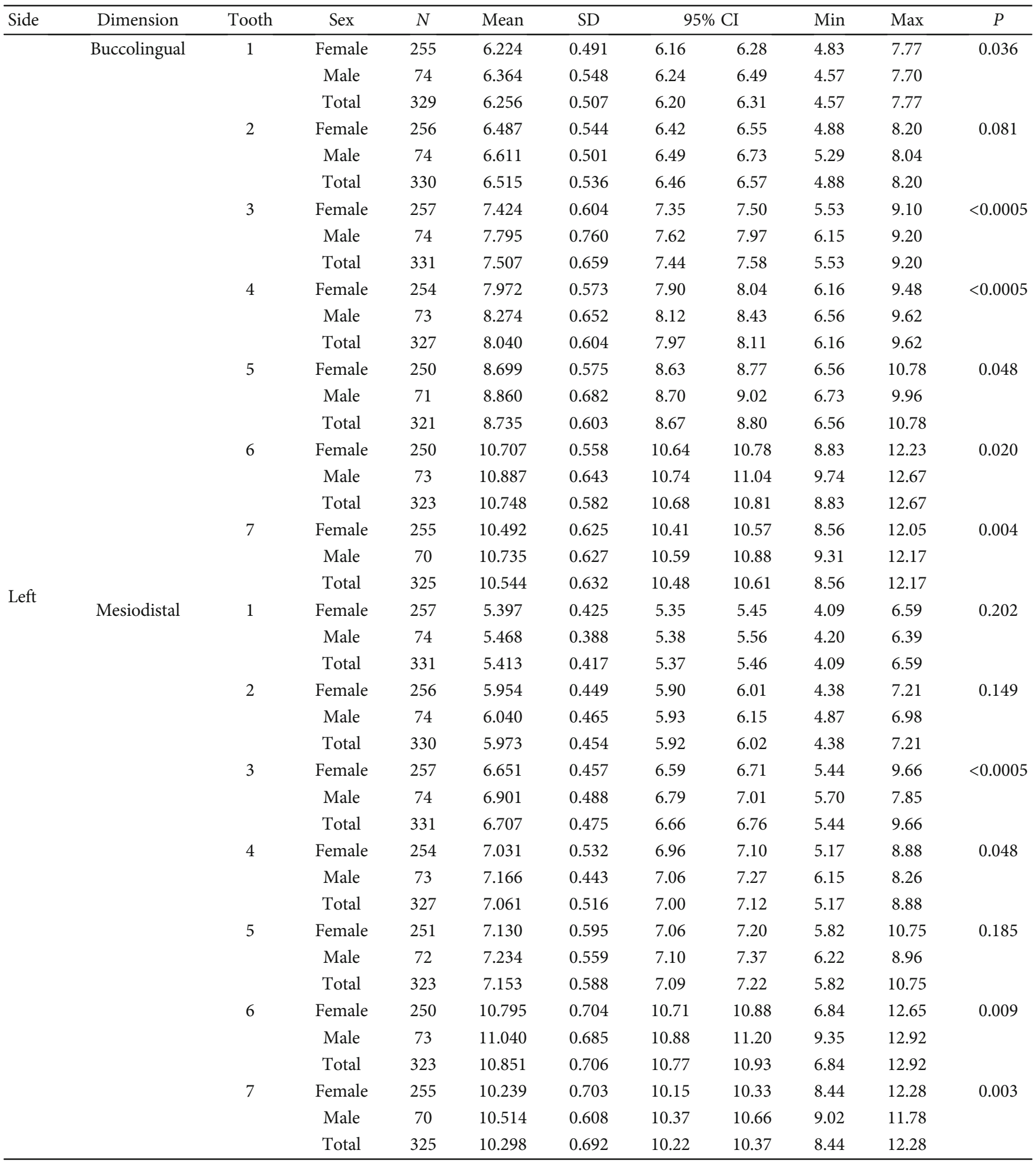

Tooth numbers 1 to 7 indicate the most anterior to the most posterior teeth. SD: standard deviation; CI: confidence interval; Min: minimum; Max: maximum. 


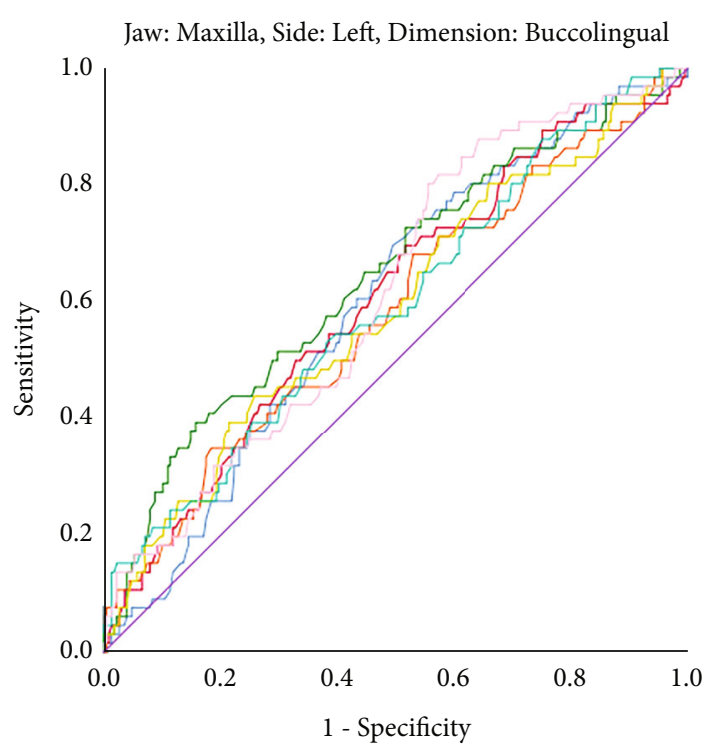

Jaw: Maxilla, Side: Left, Dimension: Mesiodistal

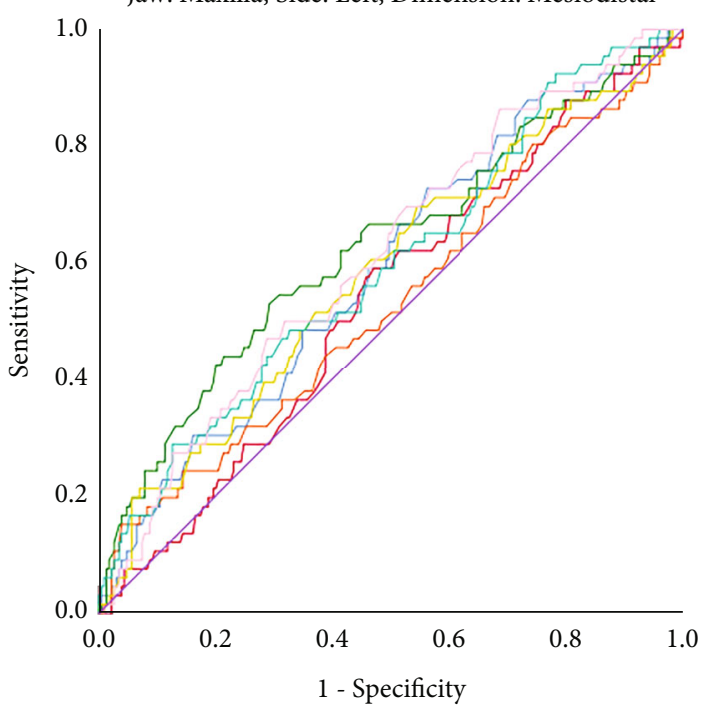

Source of the curve

$\begin{array}{ll}\text { — Central } & \text { Second premolar } \\ \text { L Lateral } & \text { First molar } \\ \text { Canine } & \text { Second molar } \\ \text { - First premolar } & \text { - Reference line }\end{array}$
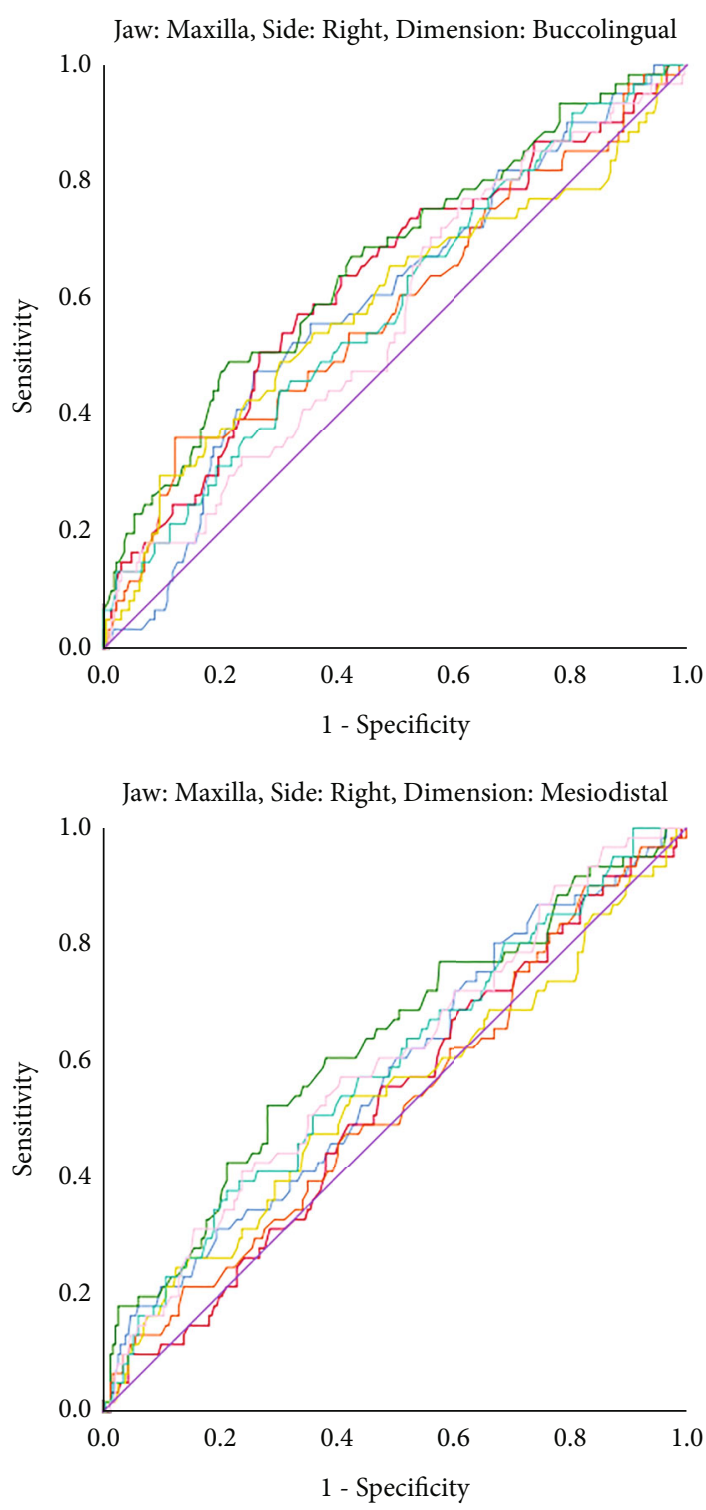

FIGURE 1: ROC curves of all the assessed mesiodistal and buccolingual dimensions of all the teeth in the left and right sides of the maxilla.

of the mesiodistal widths of the anterior 12 teeth (6-6) in the maxilla and also in the mandible were calculated. The overall Bolton ratio was computed as " $100 \times$ the sum of the mesiodistal diameters of the mandibular first 12 teeth $(6-6$, from the right first molar to the left first molar)/the sum of the mesiodistal dimensions of the maxillary first 12 teeth" [7-10]. The sums of the mesiodistal widths of the bimaxillary bilateral first premolar, second premolar, and first molar were calculated. The posterior Bolton ratio was calculated as " $100 \times$ the sum of the mesiodistal measurements of the mandibular premolars and first molars/the sum of the mesiodistal widths of the maxillary premolars and first molars" $[33,34]$.

2.1. Interexaminer Reproducibility Assessment. A second observer (FG) measured all the buccolingual and mesiodistal dimensions in all teeth of 35 randomly selected patients (4 quadrants, each). The intraclass correlation coefficient (a total of 28 Cronbach alpha values) showed excellent and high interobserver agreements between the two observers in most examinations (12 out of 28 Cronbach alpha values $>0.9$, 11 other 
TABLE 3: The areas under ROC curves and the cut-off points for sex determination (mm).

\begin{tabular}{|c|c|c|c|c|c|c|c|c|c|}
\hline Jaw & Side & Dimension & Tooth & Area & SE & $P$ & \multicolumn{2}{|c|}{$95 \% \mathrm{CI}$} & Cut-off (mm) \\
\hline \multirow{28}{*}{ Maxilla } & \multirow{14}{*}{ Right } & \multirow{8}{*}{ Buccolingual } & Central & 0.596 & 0.040 & 0.021 & 0.517 & 0.675 & 7.715 \\
\hline & & & Lateral & 0.628 & 0.041 & 0.002 & 0.547 & 0.709 & 6.950 \\
\hline & & & Canine & 0.662 & 0.040 & $<0.0005$ & 0.584 & 0.741 & 8.665 \\
\hline & & & First premolar & 0.587 & 0.043 & 0.037 & 0.502 & 0.672 & 9.915 \\
\hline & & & Second premolar & 0.590 & 0.045 & 0.031 & 0.502 & 0.677 & 10.175 \\
\hline & & & First molar & 0.589 & 0.041 & 0.032 & 0.509 & 0.670 & 11.715 \\
\hline & & & Second molar & 0.567 & 0.041 & 0.107 & 0.487 & 0.648 & - \\
\hline & & & Central & 0.575 & 0.041 & 0.072 & 0.494 & 0.656 & - \\
\hline & & \multirow{7}{*}{ Mesiodistal } & Lateral & 0.526 & 0.041 & 0.527 & 0.446 & 0.606 & - \\
\hline & & & Canine & 0.628 & 0.041 & 0.002 & 0.547 & 0.710 & 7.930 \\
\hline & & & First premolar & 0.526 & 0.042 & 0.528 & 0.444 & 0.609 & - \\
\hline & & & Second premolar & 0.536 & 0.044 & 0.383 & 0.449 & 0.623 & - \\
\hline & & & First molar & 0.590 & 0.041 & 0.030 & 0.509 & 0.671 & 10.275 \\
\hline & & & Second molar & 0.598 & 0.041 & 0.018 & 0.518 & 0.678 & 10.235 \\
\hline & \multirow{14}{*}{ Left } & & Central & 0.602 & 0.038 & 0.011 & 0.529 & 0.676 & 7.355 \\
\hline & & \multirow{6}{*}{ Buccolingual } & Lateral & 0.606 & 0.039 & 0.009 & 0.529 & 0.683 & 6.535 \\
\hline & & & Canine & 0.643 & 0.040 & $<0.0005$ & 0.566 & 0.721 & 8.780 \\
\hline & & & First premolar & 0.583 & 0.041 & 0.039 & 0.503 & 0.663 & 9.845 \\
\hline & & & Second premolar & 0.591 & 0.041 & 0.024 & 0.512 & 0.671 & 9.865 \\
\hline & & & First molar & 0.596 & 0.040 & 0.018 & 0.518 & 0.674 & 11.505 \\
\hline & & & Second molar & 0.616 & 0.037 & 0.004 & 0.543 & 0.690 & 11.235 \\
\hline & & \multirow{7}{*}{ Mesiodistal } & Central & 0.591 & 0.039 & 0.025 & 0.513 & 0.668 & 8.570 \\
\hline & & & Lateral & 0.537 & 0.039 & 0.363 & 0.460 & 0.614 & - \\
\hline & & & Canine & 0.627 & 0.041 & 0.002 & 0.546 & 0.708 & 7.835 \\
\hline & & & First premolar & 0.532 & 0.042 & 0.422 & 0.450 & 0.615 & - \\
\hline & & & Second premolar & 0.583 & 0.041 & 0.041 & 0.503 & 0.663 & 7.365 \\
\hline & & & First molar & 0.595 & 0.040 & 0.019 & 0.516 & 0.673 & 10.815 \\
\hline & & & Second molar & 0.611 & 0.039 & 0.006 & 0.536 & 0.687 & 10.155 \\
\hline \multirow{20}{*}{ Mandible } & \multirow{14}{*}{ Right } & \multirow{8}{*}{ Buccolingual } & Central & 0.578 & 0.043 & 0.056 & 0.494 & 0.662 & - \\
\hline & & & Lateral & 0.572 & 0.043 & 0.078 & 0.488 & 0.655 & - \\
\hline & & & Canine & 0.652 & 0.043 & $<0.0005$ & 0.568 & 0.736 & 7.905 \\
\hline & & & First premolar & 0.652 & 0.041 & $<0.0005$ & 0.572 & 0.732 & 8.285 \\
\hline & & & Second premolar & 0.572 & 0.045 & 0.078 & 0.484 & 0.660 & - \\
\hline & & & First molar & 0.594 & 0.042 & 0.021 & 0.512 & 0.677 & 11.455 \\
\hline & & & Second molar & 0.629 & 0.039 & 0.002 & 0.553 & 0.705 & 10.755 \\
\hline & & & Central & 0.536 & 0.040 & 0.372 & 0.457 & 0.615 & - \\
\hline & & \multirow{6}{*}{ Mesiodistal } & Lateral & 0.577 & 0.041 & 0.059 & 0.497 & 0.656 & - \\
\hline & & & Canine & 0.720 & 0.036 & $<0.0005$ & 0.650 & 0.790 & 6.835 \\
\hline & & & First premolar & 0.575 & 0.040 & 0.066 & 0.497 & 0.653 & - \\
\hline & & & Second premolar & 0.563 & 0.041 & 0.119 & 0.483 & 0.644 & - \\
\hline & & & First molar & 0.605 & 0.040 & 0.010 & 0.526 & 0.684 & 10.885 \\
\hline & & & Second molar & 0.620 & 0.038 & 0.003 & 0.545 & 0.695 & 10.275 \\
\hline & \multirow{6}{*}{ Left } & \multirow{6}{*}{ Buccolingual } & Central & 0.617 & 0.039 & 0.003 & 0.540 & 0.695 & 6.175 \\
\hline & & & Lateral & 0.610 & 0.039 & 0.006 & 0.534 & 0.686 & 6.575 \\
\hline & & & Canine & 0.683 & 0.041 & $<0.0005$ & 0.604 & 0.763 & 7.765 \\
\hline & & & First premolar & 0.673 & 0.039 & $<0.0005$ & 0.596 & 0.749 & 8.275 \\
\hline & & & Second premolar & 0.606 & 0.043 & 0.008 & 0.522 & 0.689 & 9.025 \\
\hline & & & First molar & 0.571 & 0.042 & 0.077 & 0.489 & 0.652 & - \\
\hline
\end{tabular}


TABLE 3: Continued.

\begin{tabular}{|c|c|c|c|c|c|c|c|c|c|}
\hline \multirow[t]{2}{*}{ Jaw } & \multirow[t]{2}{*}{ Side } & \multirow[t]{2}{*}{ Dimension } & \multirow{2}{*}{$\begin{array}{c}\text { Tooth } \\
\text { Second molar }\end{array}$} & \multirow{2}{*}{$\begin{array}{l}\text { Area } \\
0.603\end{array}$} & \multirow{2}{*}{$\begin{array}{c}\text { SE } \\
0.040\end{array}$} & \multirow{2}{*}{$\begin{array}{c}P \\
0.010\end{array}$} & \multicolumn{2}{|c|}{$95 \% \mathrm{CI}$} & \multirow{2}{*}{$\frac{\text { Cut-off }(\mathrm{mm})}{10.610}$} \\
\hline & & & & & & & 0.526 & 0.681 & \\
\hline & & & Central & 0.553 & 0.038 & 0.183 & 0.478 & 0.628 & - \\
\hline & & & Lateral & 0.547 & 0.042 & 0.238 & 0.465 & 0.629 & - \\
\hline & & & Canine & 0.668 & 0.041 & $<0.0005$ & 0.589 & 0.748 & 6.960 \\
\hline & & Mesiodistal & First premolar & 0.585 & 0.038 & 0.033 & 0.511 & 0.658 & 6.965 \\
\hline & & & Second premolar & 0.554 & 0.041 & 0.172 & 0.473 & 0.635 & - \\
\hline & & & First molar & 0.598 & 0.039 & 0.014 & 0.522 & 0.673 & 10.910 \\
\hline & & & Second molar & 0.631 & 0.037 & 0.001 & 0.559 & 0.703 & 10.275 \\
\hline
\end{tabular}

SE: standard error; CI: confidence interval for the AUC. Measurements below the cut-off points belong to women.

Cronbach alpha values between 0.8 and 0.9 , four remaining Cronbach alpha values between 0.75 and 0.8 , and one last Cronbach alpha $=0.664$, all $P$ values $<0.0005)$.

2.2. Statistical Analyses. Statistical analysis was performed using SPSS 25 (IBM, Armonk, NY, USA). Descriptive statistics and 95\% confidence intervals (CIs) were calculated. Since age might affect some crown dimensions [35], the ages of males and females were compared using an unpaired $t$ -test. Crown dimensions were compared between men and women, using an unpaired $t$-test. A receiver operating characteristic (ROC) curve was used to estimate the areas under the curve (AUC) and cut-off points for the identification of individuals' sex based on dental measurements. A partial correlation coefficient, controlling for the variable sex, was used to assess correlations between age and crown measurements as well as correlations among dental measurements. In all of these analyses, the analyses for the right and left sides were conducted separately.

2.2.1. Associations between Metric Traits with the Angle Classification and Crowding. The averages were calculated for measurements on the left and right sides. Associations between these average buccolingual or average mesiodistal dimensions with the skeletal Angle classes, crowding, and microdontia were assessed using an independent-sample $t$ -test as well as a one-way analysis of variance (ANOVA) followed by a Tukey post hoc test.

2.2.2. Bolton Anterior, Posterior, and Overall Ratios. An unpaired $t$-test and a one-way ANOVA followed by a Tukey test were used to compare the Bolton ratios between males and females and among the Angle classes, respectively. The effects of sex and the Angle classes on Bolton ratios were assessed using a multiple linear regression. Correlations between age and Bolton ratios were assessed using a Pearson correlation coefficient. The Bolton ratios were compared with the original ratios reported by Bolton [10] using an unpaired $t$-test. The level of significance was set at 0.05 .

\section{Results}

There were 74 males and 257 females included in the study. The mean (SD) age of patients was $19.21 \pm 4.87$ years (range: $12-35)$. Mean ages of men and women were 18.29 \pm 20.49 and $18.55 \pm 19.76$ years, respectively. The sexes were balanced in terms of age ( $t$-test, $P=0.716)$. Of the patients, $182(55.7 \%), 127(38.8 \%)$, and 18 (5.5\%) were classes I, II, and III, respectively (the Angle classifications of four patients were not entered). Crowding was observed in 89 out of 331 cases $(26.9 \%)$.

Numerous teeth had sex dimorphism in terms of buccolingual or mesiodistal measurements ( $t$-test, $P$ values $\leq 0.05$, Tables 1 and 2). The few measurements without sex dimorphism in the maxilla were as follows: mesiodistal dimensions of the lateral and both premolars on the right and the lateral and first premolars on the left. In the mandible, the sizes without sex dimorphism were as follows: the buccolingual widths of the central, lateral, and second premolars on the right, and the left lateral, as well as the mesiodistal measurements of the right central and premolars, and the left incisors and second premolar.

The $t$-test did not show any significant differences between the left versus right sides in any of the teeth of either the maxilla or the mandible (all $P$ values $>0.05$ ).

The statistically significant areas under the ROC curves indicated that numerous teeth can be used for sex determination (Figure 1, Table 3) although AUCs were not considerably large in many of the statistically significant measurements. In each measurement of each quadrant, the canine had the greatest area under the curve among all other teeth. The highest AUC belonged to the mesiodistal dimension of the mandibular canine. The measurements with AUCs $\geq 64 \%$ were as follows: the buccolingual size of the right and left maxillary canines and the buccolingual size of the right and left mandibular canines and the right and left mandibular first premolars, as well as the mesiodistal dimension of the right and left mandibular canines (Figures 1 and 2, Table 3). The cut-off points for determining the sex based on the buccolingual and mesiodistal measurements of the maxillary and mandibular permanent teeth are presented in Table 3.

Controlling for the role of sex, age was negatively and weakly correlated with buccolingual widths of the right maxillary first premolar $(r=-0.119, P=0.045$, partial correlation coefficient) and second premolar $(r=-0.121, P=0.040$, Figure 3(a)), the left maxillary first premolar $(r=-0.131, P=$ $0.025)$ and second premolar $(r=-0.145, \quad P=0.013$, Figure 3(b)), the right mandibular second premolar $(r=-0.138, P=0.017)$ and first molar $(r=-0.155, P=0.007$, 

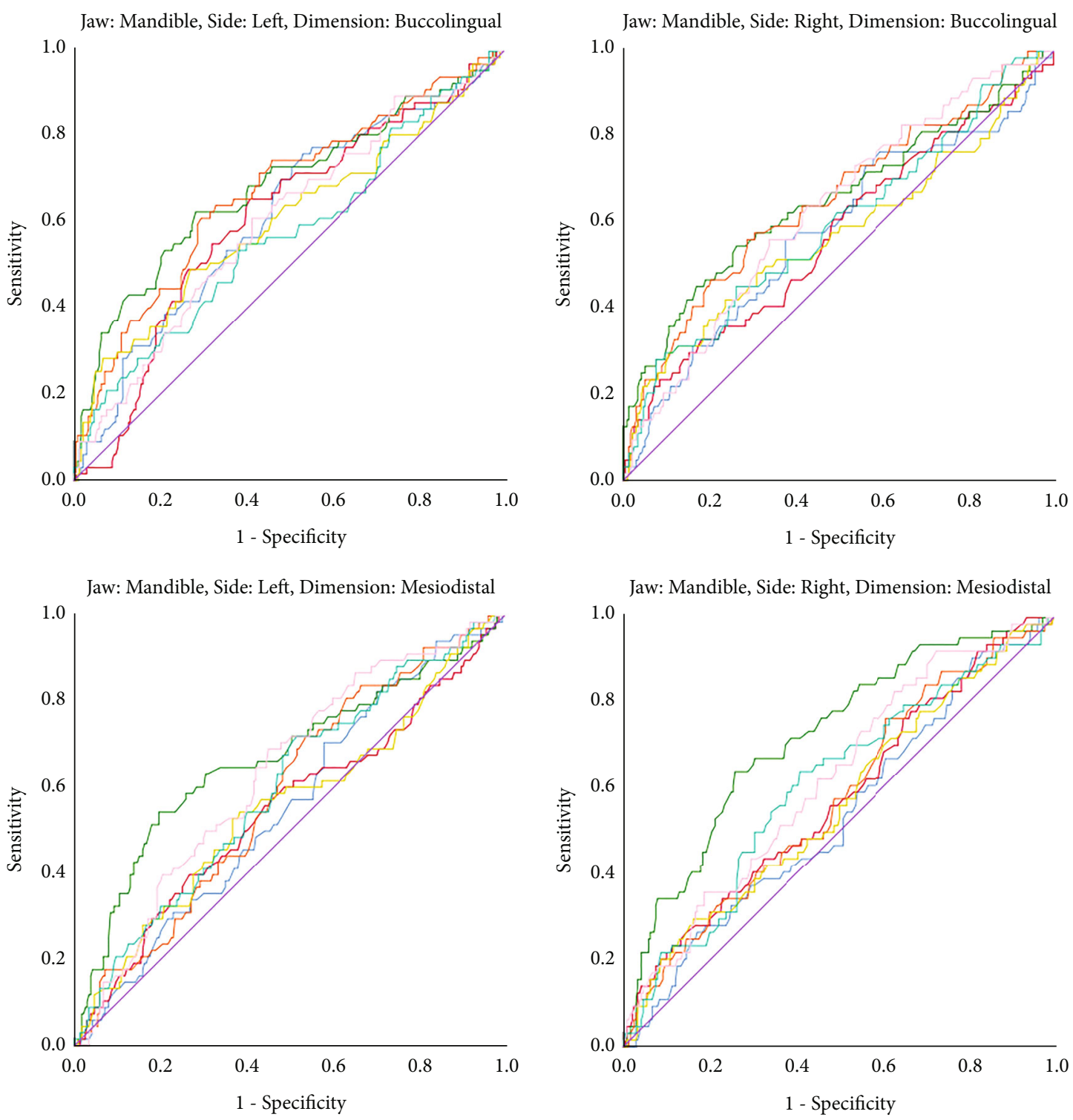

Source of the curve

$\begin{array}{ll}\text { — Central } & \text { Second premolar } \\ \text { L Lateral } & \text { First molar } \\ \text { Canine } & \text { Second molar } \\ \text { First premolar } & - \text { Reference line }\end{array}$

Figure 2: ROC curves of all the assessed mesiodistal and buccolingual dimensions of all the teeth in the left and right sides of the mandible.

Figure 3(c)), and the left mandibular second premolar $(r=-0.131, P=0.023)$ and first molar $(r=-0.135, P=0.019$, Figure 3(d), Appendix 1).

Age was also correlated negatively, significantly, and weakly with mesiodistal dimensions of the right maxillary first premolar $(r=-0.124, P=0.034)$ and first molar $(r=-0.185$, $P=0.002$, Figure 4(a)); the left maxillary central $(r=-0.159$, $P=0.006)$, canine $(r=-0.129, P=0.027)$, first premolar $(r=-0.133, P=0.023)$, and first molar $(r=-0.134, P=$ 0.022 , Figure 4(b)); the right mandibular lateral $(r=-0.177$, $P=0.002)$, first premolar $(r=-0.149, P=0.010)$; and first molar $(r=-0.159, P=0.006$, Figure $4(\mathrm{c}))$; and the left mandibular central $(r=-0.163, P=0.004)$, lateral $(r=-0.131, P$ $=0.022)$, and first premolar $(r=-0.175, \quad P=0.002$, Figure 4(d), Appendix 1).

3.1. Associations between Metric Traits with the Angle Classification. According to the ANOVA, the teeth that had different sizes in different classes were the maxillary lateral (buccolingual measurement only) and the mandibular central and lateral (buccolingual only, Table 4). According to the Tukey post hoc test, the buccolingual dimension of maxillary 


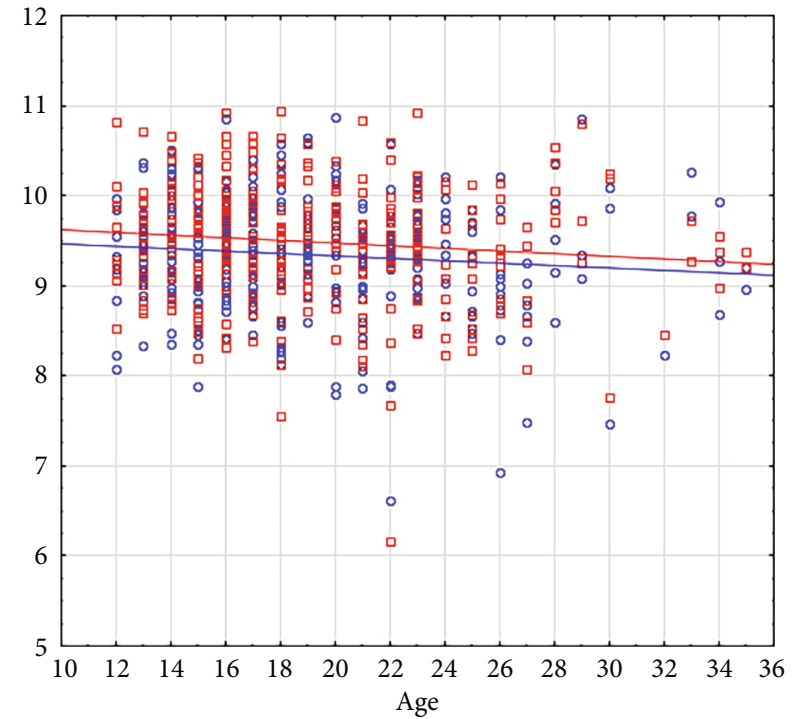

Q First premolar

Second premolar

(a)

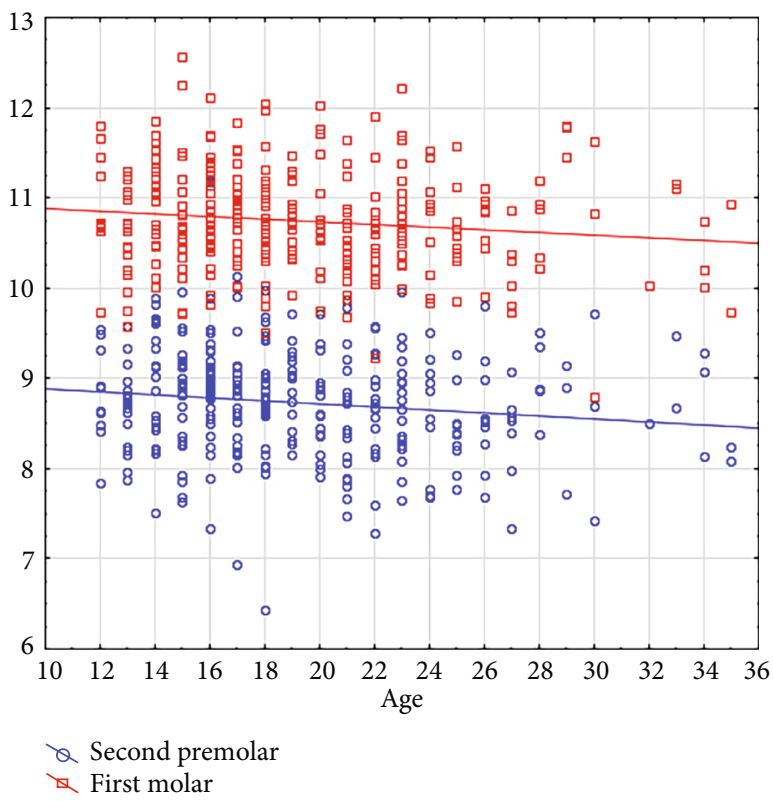

(c)

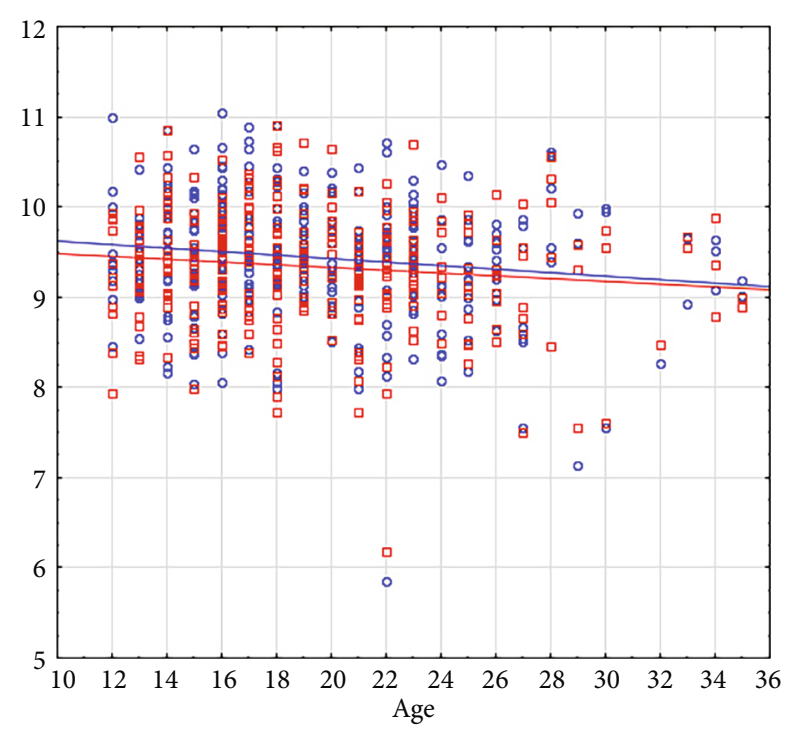

Q Second premolar

¿ First premolar

(b)

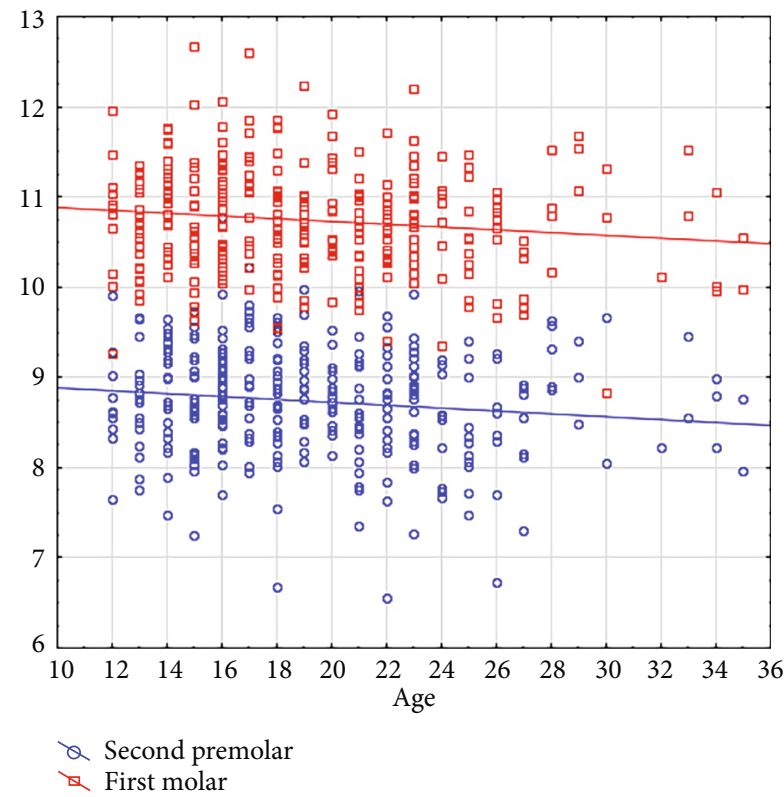

(d)

Figure 3: Scatterplots showing the significant correlations between age (the $X$ axis, year) and the buccolingual widths (the $Y$ axis, mm), in (a) the right maxillary teeth, (b) the left maxillary teeth, (c) the right mandibular teeth, and (d) the left mandibular teeth.

lateral differed only between classes I and II $(P=0.030)$. Similarly, the buccolingual width of the mandibular central differed only between classes I and II $(P=0.032)$. The buccolingual diameter of the mandibular lateral differed between classes I and II ( $P=0.025$, Table 4$)$.

All dental measurements were similar between cases with and without crowding ( $t$-test, $P>0.05$, Table 5$)$.

All "left/right-averaged" buccolingual and mesiodistal measurements of all the 14 teeth (the maxillary and mandibular centrals to the second molars, regardless of their right and left sides) differed significantly between the cases with microdontia versus those without it ( $t$-test, $P \leq 0.002$, Table 6).

There were significant positive correlations among all different crown measurements of all the assessed teeth (Appendix 1).

3.2. Bolton Indices. Between men and women, there was no significant difference in terms of Bolton ratios ( $t$-test, Table 7). There was no significant difference among different Angle classes in terms of the overall or anterior Bolton ratios (Table 7). 


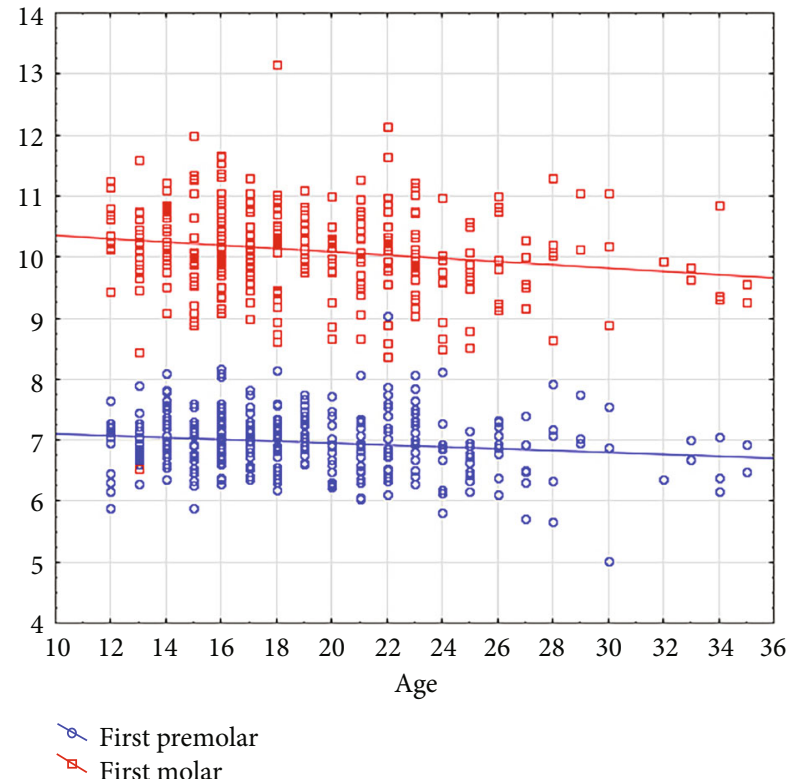

(a)

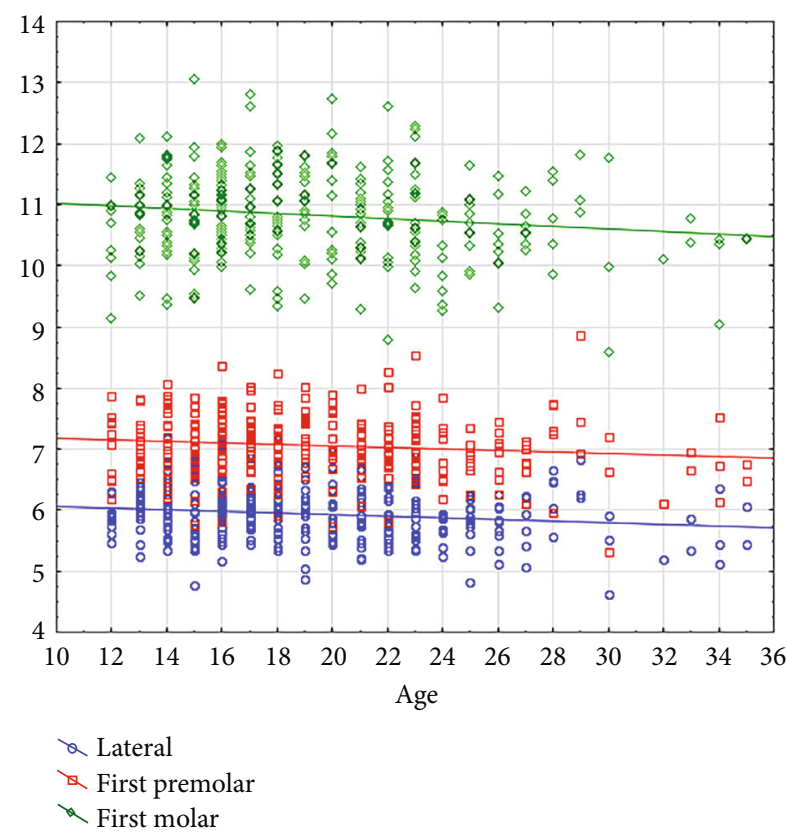

(c)

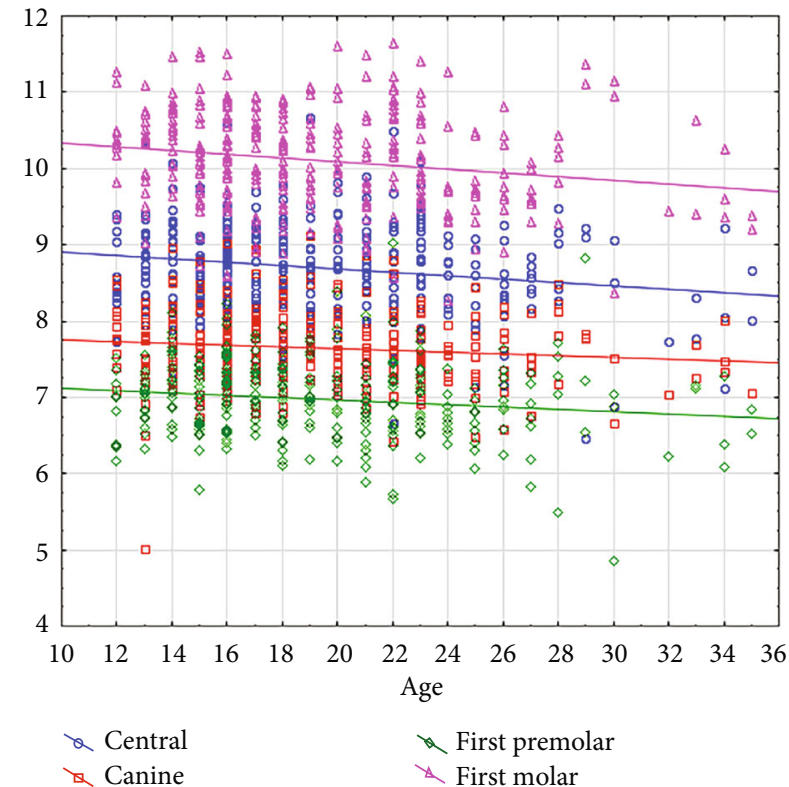

(b)

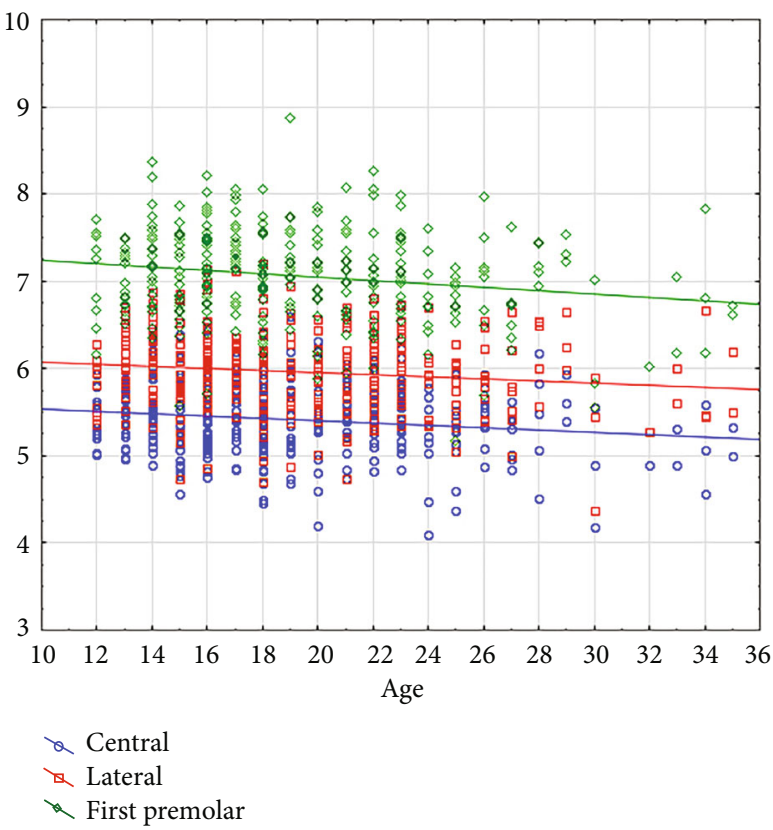

(d)

FIGURE 4: Scatterplots illustrating the significant correlations between age (the $X$ axis, year) and the mesiodistal widths (the $Y$ axis, mm), in (a) the right maxillary teeth, (b) the left maxillary teeth, (c) the right mandibular teeth, and (d) the left mandibular teeth.

However, the posterior Bolton ratios differed significantly across the Angle classes (ANOVA, Table 7). The Tukey test showed that the mean posterior Bolton ratio in class II patients was smaller than those in both class I $(P=0.029)$ and class III patients $(P=0.045)$. There was no significant difference between classes I and III $(P=0.369$, Tukey). The multiple regression did not detect any significant effect of sex $(P \geq 0.080)$ or the Angle classification $(P \geq 0.304)$ on any Bolton ratios.

There was no correlation between ages with any Bolton ratios (Pearson $R \leq 0.064, P \geq 0.297$ ). The correlations between the overall Bolton index with the anterior Bolton index (Pearson $R=0.696, P<0.00000005)$ and the posterior Bolton index ( $R=0.740, P<0.00000005)$ were significant. However, the was no significant correlation between the anterior and posterior Bolton ratios $(R=0.045, P=0.459)$.

The unpaired $t$-test was used to compare the sexes within each Angle class separately (Table 8). Because of the small number of class III males, no comparisons were done for class III cases. As the only significant comparison, the anterior Bolton ratio of class II men was significantly larger than that of class II women $(P=0.014$, Table 8$)$. 
TABle 4: Descriptive statistics and 95\% CIs for dental measurements (averages of the right and left sides, mm) in different Angle classes. The classes are compared using the one-way ANOVA.

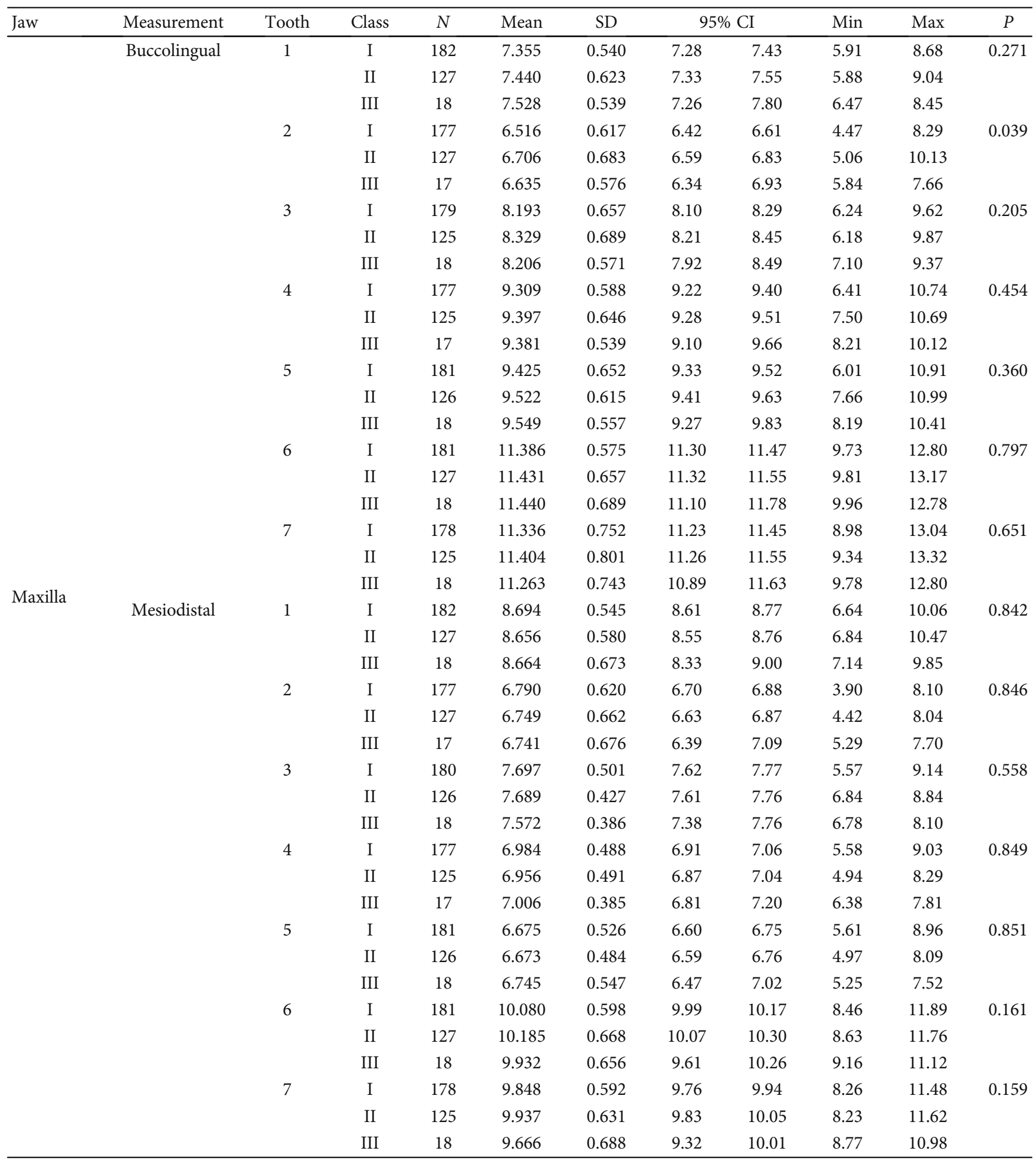


TABLE 4: Continued.

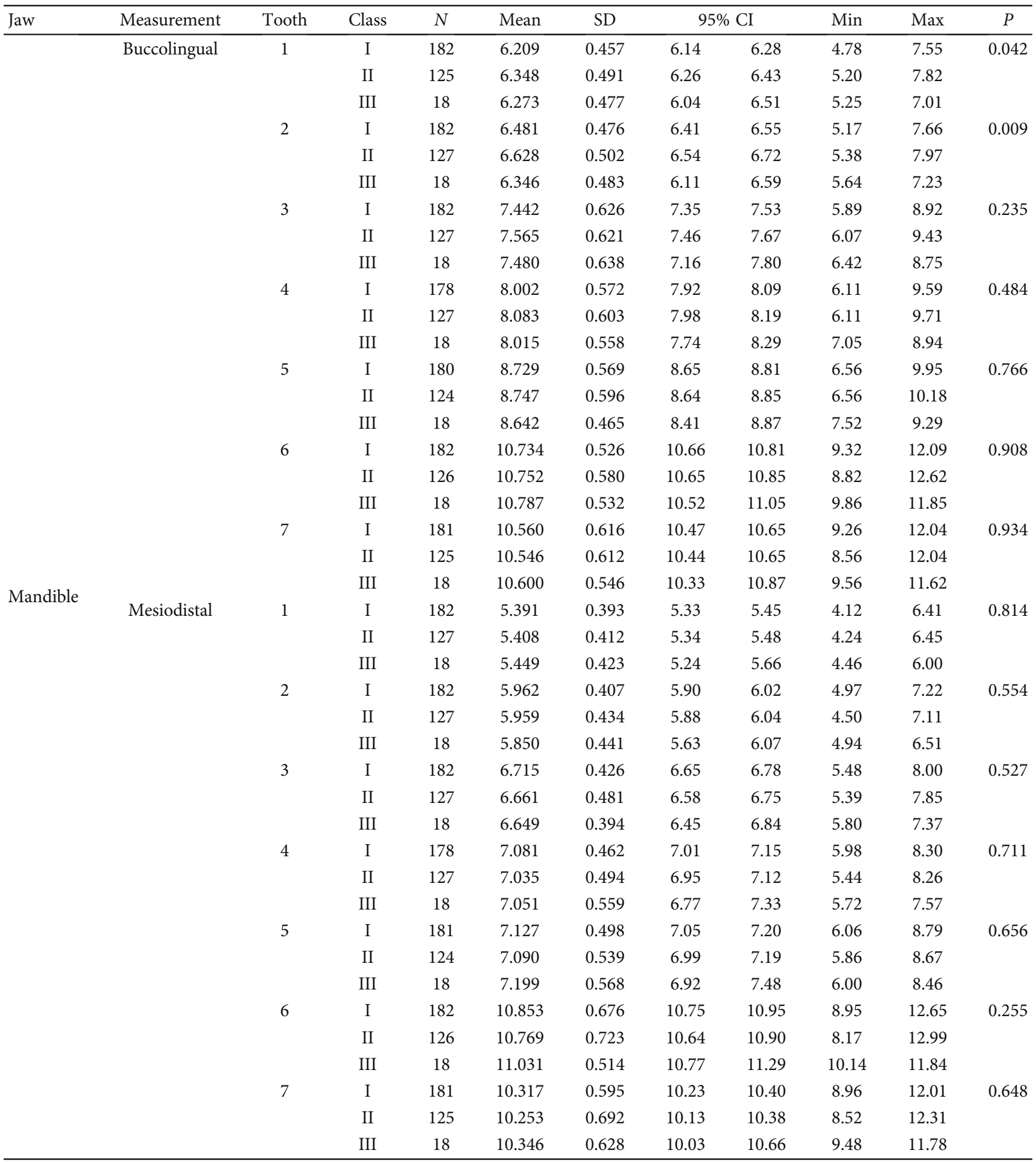

Tooth numbers 1 to 7 indicate the central to the second molar teeth. SD: standard deviation; CI: confidence interval; Min: minimum; Max: maximum. 
TABle 5: Descriptive statistics and 95\% CIs for dental measurements (averages of the right and left sides, mm) in crowded versus noncrowded dentitions. The groups are compared using the $t$-test.

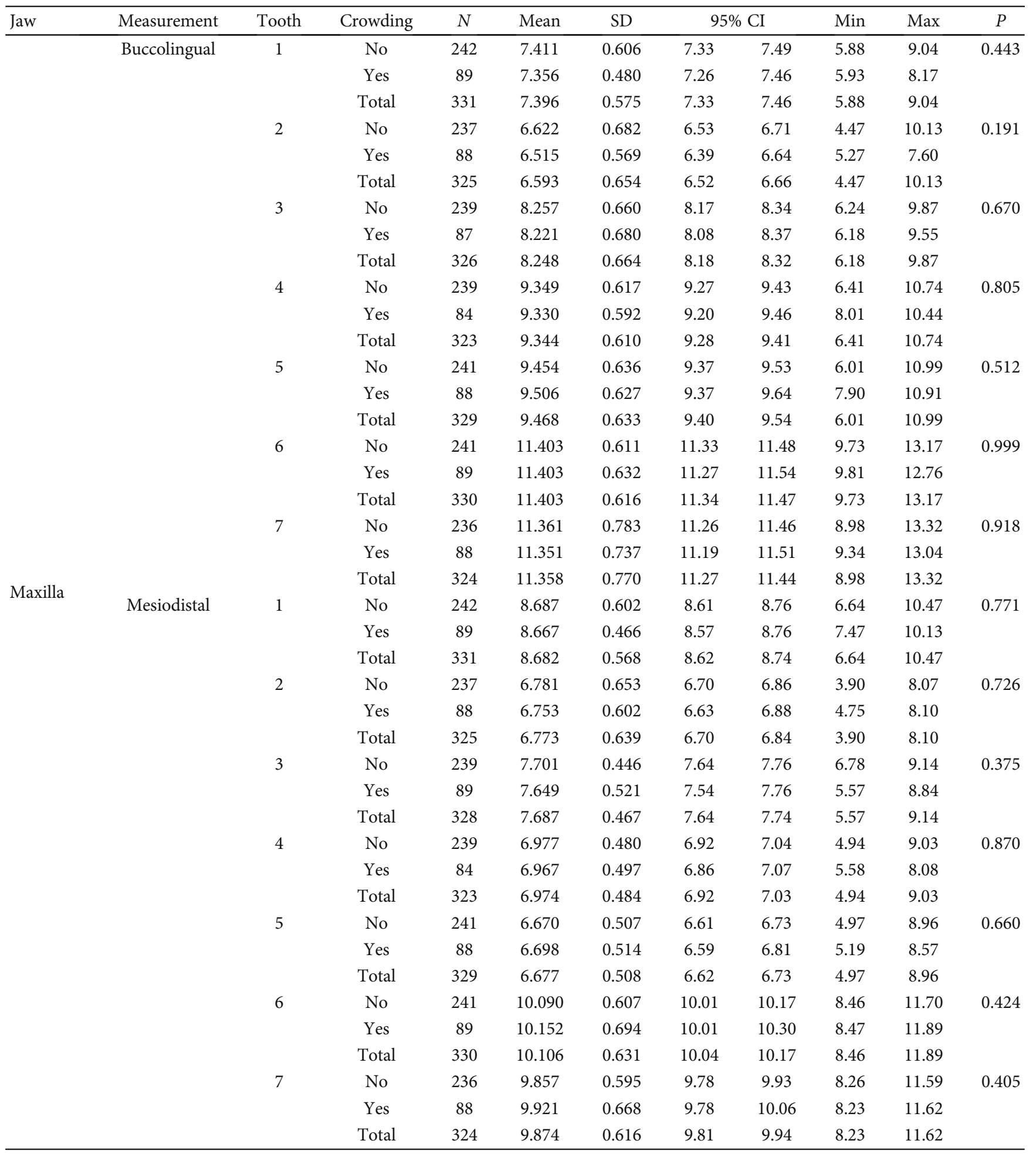


TABLE 5: Continued.

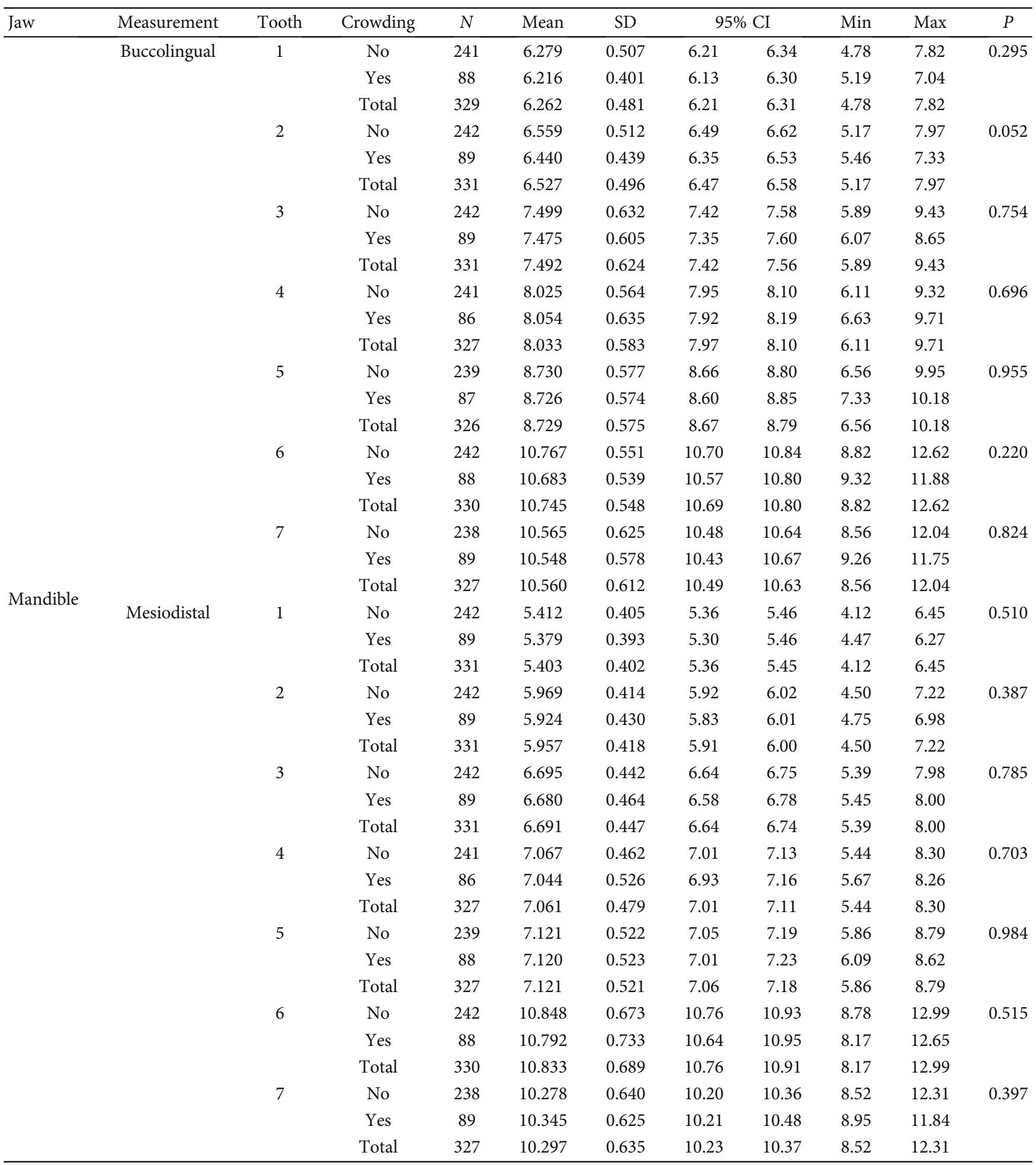

Tooth numbers 1 to 7 indicate the central to the second molar teeth. SD: standard deviation; CI: confidence interval; Min: minimum; Max: maximum. 
TABLE 6: Descriptive statistics and 95\% CIs for dental sizes (averages of the right and left sides, $\mathrm{mm}$ ) in cases with and without microdontia. The groups are compared using the $t$-test.

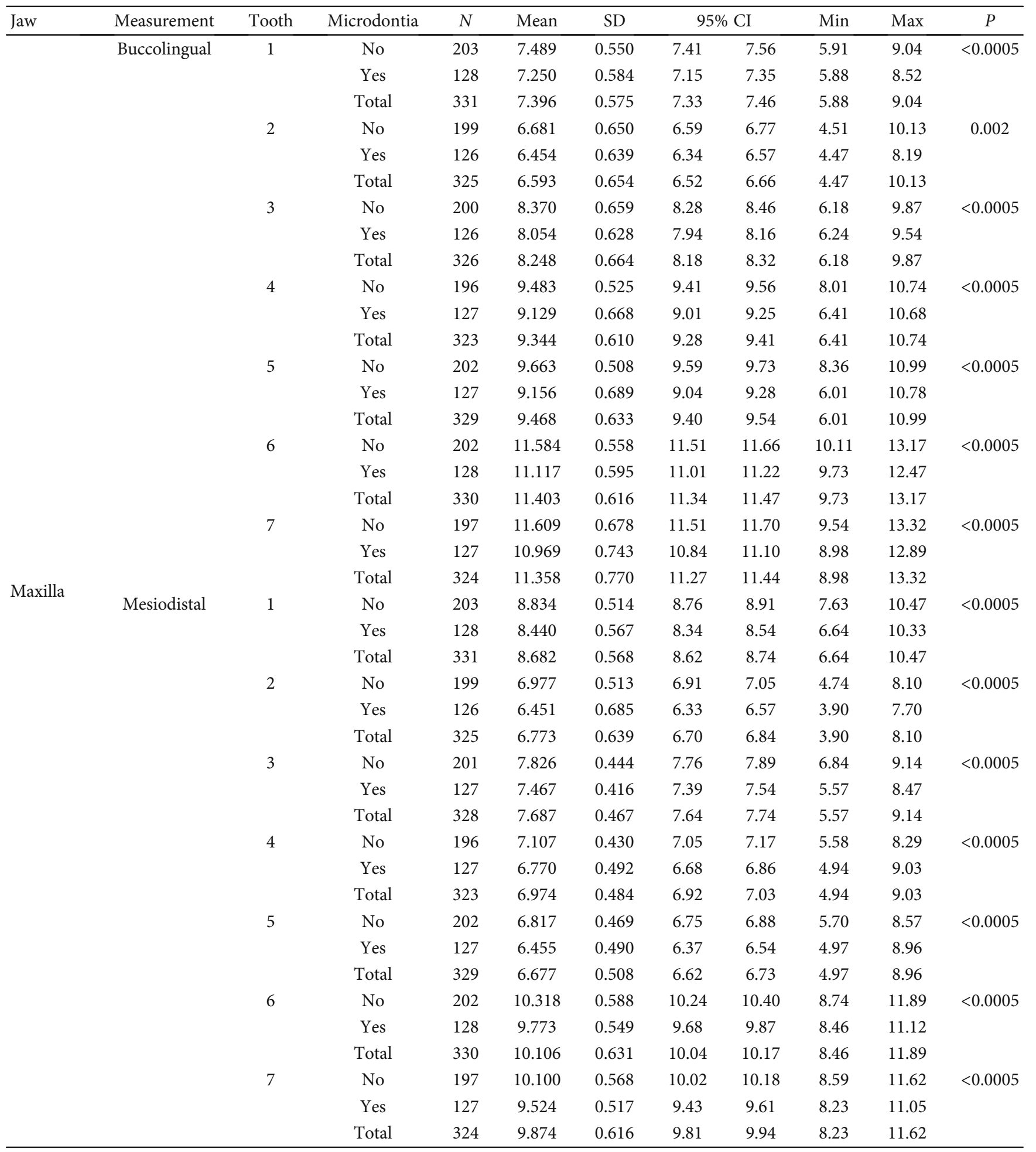


TABLE 6: Continued.

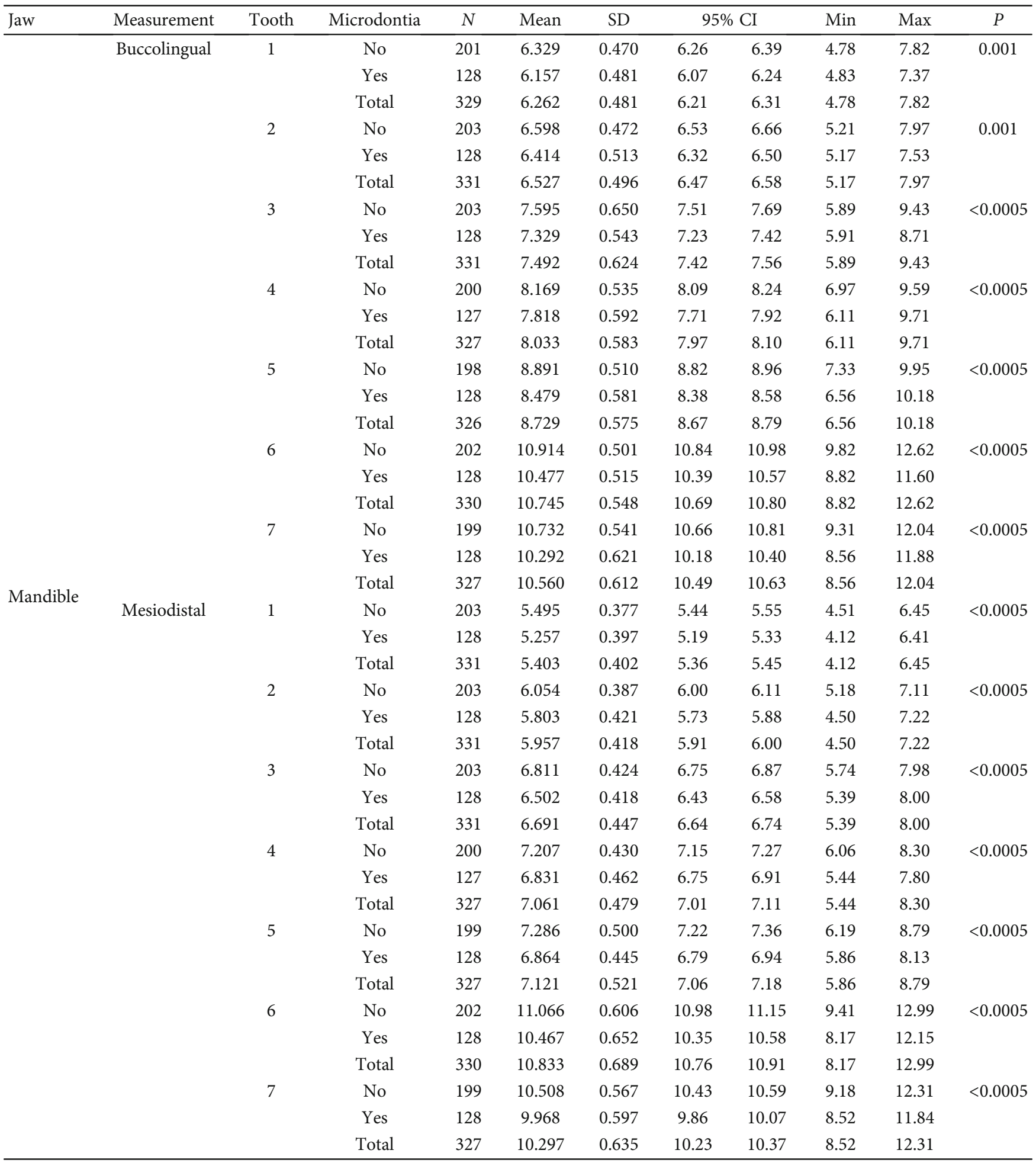

Tooth numbers 1 to 7 denote the central to the second molar teeth. SD: standard deviation; CI: confidence interval; Min: minimum; Max: maximum. 
TABle 7: The Bolton ratios in men, women, and different Angle classes.

\begin{tabular}{|c|c|c|c|c|c|c|c|c|c|}
\hline Bolton ratio & Variables & $N$ & Mean & $\mathrm{SD}$ & \multicolumn{2}{|c|}{$95 \% \mathrm{CI}$} & Min & Max & $P$ \\
\hline \multirow{3}{*}{ Overall } & Female & 210 & 91.78 & 2.48 & 91.44 & 92.12 & 83.97 & 99.09 & 0.229 \\
\hline & Male & 58 & 92.22 & 2.42 & 91.58 & 92.85 & 86.32 & 99.87 & \\
\hline & Total & 268 & 91.87 & 2.47 & 91.58 & 92.17 & 83.97 & 99.87 & \\
\hline \multirow{3}{*}{ Anterior } & Female & 210 & 77.86 & 3.11 & 77.44 & 78.29 & 69.00 & 89.43 & 0.059 \\
\hline & Male & 58 & 78.74 & 3.02 & 77.94 & 79.53 & 71.45 & 87.61 & \\
\hline & Total & 268 & 78.05 & 3.11 & 77.68 & 78.43 & 69.00 & 89.43 & \\
\hline \multirow{3}{*}{ Posterior } & Female & 210 & 105.42 & 3.77 & 104.91 & 105.93 & 96.20 & 114.43 & 0.995 \\
\hline & Male & 58 & 105.41 & 3.83 & 104.41 & 106.42 & 97.14 & 115.59 & \\
\hline & Total & 268 & 105.42 & 3.77 & 104.96 & 105.87 & 96.20 & 115.59 & \\
\hline \multirow{3}{*}{ Overall } & Class I & 142 & 91.96 & 2.43 & 91.56 & 92.37 & 86.32 & 99.09 & 0.083 \\
\hline & Class II & 110 & 91.55 & 2.41 & 91.10 & 92.01 & 83.97 & 99.87 & \\
\hline & Class III & 13 & 93.03 & 2.50 & 91.52 & 94.54 & 88.94 & 97.73 & \\
\hline \multirow{3}{*}{ Anterior } & Class I & 142 & 77.90 & 2.98 & 77.41 & 78.40 & 71.45 & 86.06 & 0.667 \\
\hline & Class II & 110 & 78.16 & 3.30 & 77.54 & 78.79 & 69.00 & 89.43 & \\
\hline & Class III & 13 & 78.56 & 2.96 & 76.77 & 80.35 & 74.48 & 85.40 & \\
\hline \multirow{3}{*}{ Posterior } & Class I & 142 & 105.80 & 3.64 & 105.19 & 106.40 & 96.78 & 112.49 & 0.008 \\
\hline & Class II & 110 & 104.60 & 3.69 & 103.90 & 105.30 & 96.20 & 115.59 & \\
\hline & Class III & 13 & 107.19 & 4.16 & 104.67 & 109.70 & 100.42 & 112.31 & \\
\hline
\end{tabular}

SD: standard deviation; CI: confidence interval; Min: minimum; Max: maximum. The $P$ values for comparisons between men and women are calculated using the unpaired $t$-test. The $P$ values for comparisons across Angle classes are calculated using the one-way ANOVA.

TABle 8: The Bolton indices in men versus women within different Angle classes.

\begin{tabular}{|c|c|c|c|c|c|c|c|c|c|c|}
\hline Angle classes & Bolton ratio & Sex & $N$ & Mean & SD & \multicolumn{2}{|c|}{$95 \%$ CI } & Min & Max & $P$ \\
\hline \multirow{6}{*}{ Class I } & \multirow{2}{*}{ Overall } & Female & 115 & 91.91 & 2.48 & 91.45 & 92.37 & 86.40 & 99.09 & 0.586 \\
\hline & & Male & 27 & 92.19 & 2.22 & 91.32 & 93.07 & 86.32 & 95.72 & \\
\hline & \multirow{2}{*}{ Anterior } & Female & 115 & 77.89 & 2.97 & 77.34 & 78.44 & 72.16 & 86.06 & 0.909 \\
\hline & & Male & 27 & 77.96 & 3.09 & 76.74 & 79.18 & 71.45 & 86.02 & \\
\hline & \multirow{2}{*}{ Posterior } & Female & 115 & 105.69 & 3.72 & 105.00 & 106.38 & 96.78 & 112.37 & 0.472 \\
\hline & & Male & 27 & 106.25 & 3.28 & 104.96 & 107.55 & 99.47 & 112.49 & \\
\hline \multirow{6}{*}{ Class II } & \multirow{2}{*}{ Overall } & Female & 82 & 91.35 & 2.35 & 90.83 & 91.86 & 83.97 & 97.67 & 0.121 \\
\hline & & Male & 28 & 92.17 & 2.53 & 91.19 & 93.15 & 87.72 & 99.87 & \\
\hline & \multirow{2}{*}{ Anterior } & Female & 82 & 77.72 & 3.33 & 76.99 & 78.45 & 69.00 & 89.43 & 0.014 \\
\hline & & Male & 28 & 79.48 & 2.92 & 78.35 & 80.61 & 74.52 & 87.61 & \\
\hline & \multirow{2}{*}{ Posterior } & Female & 82 & 104.64 & 3.60 & 103.85 & 105.43 & 96.20 & 114.43 & 0.841 \\
\hline & & Male & 28 & 104.48 & 4.01 & 102.92 & 106.03 & 97.14 & 115.59 & \\
\hline \multirow{6}{*}{ Class III } & \multirow{2}{*}{ Overall } & Female & 11 & 93.46 & 2.48 & 91.79 & 95.13 & 88.94 & 97.73 & - \\
\hline & & Male & 2 & 90.69 & 0.57 & - & - & 90.28 & 91.09 & \\
\hline & \multirow{2}{*}{ Anterior } & Female & 11 & 78.72 & 3.15 & 76.60 & 80.83 & 74.48 & 85.40 & - \\
\hline & & Male & 2 & 77.68 & 2.09 & - & - & 76.20 & 79.15 & \\
\hline & \multirow{2}{*}{ Posterior } & Female & 11 & 107.94 & 4.09 & 105.20 & 110.69 & 100.42 & 112.31 & - \\
\hline & & Male & 2 & 103.03 & 0.46 & - & - & 102.71 & 103.36 & \\
\hline
\end{tabular}

SD: standard deviation; CI: confidence interval; Min: minimum; Max: maximum. The $P$ values are calculated using the unpaired $t$-test. 
The comparison of the overall Bolton ratio of this sample (Table 7) with the original overall Bolton ratio (mean: 91.3, SD: $1.91, n=55$ ) [10] did not show a significant difference (unpaired $t$-test, $P=0.107$ ). However, the anterior Bolton ratio of this sample was significantly greater ( $t$-test, $P=$ 0.0498 , Table 7 ) than the original anterior Bolton ratio (mean: 77.2, SD: $1.65, n=55$ ) [10].

\section{Discussion}

Tooth size variation is influenced by environmental and genetic factors including race, sex, heredity, cellular changes, and bilateral asymmetry [4, 20, 36]. Environmental factors include nutrition, disease, and climate, which might affect the prenatal dental system and seem to make little change to the normal dental system [37]. The strong contribution of genetic factors to the differences in dental measurements has been shown, but the influence of environmental factors seems plausible as well. Both environmental and genetic factors play a role in the etiology of supernumerary teeth, hypodontia, megadontia, and microdontia [38]. Sizes of teeth might vary in different populations [1, 20, 39]. Sex dimorphism has been reported as ranging between $0.82 \%$ and $5.97 \%$ for all teeth [4]. An example of a sex difference is the tendency of men to have larger teeth than women, which reflects the relationship between the $\mathrm{X}$ chromosome and the $\mathrm{Y}$ chromosome. For example, men who are XXY and XYY have teeth larger than XY men [1]. Our results were in line with these suggestions.

Keiser and Julius examined mesiodistal and buccolingual tooth sizes and concluded that they could be used to determine sex [40]. Using the dental dimensions of one ethnic group might be used in other ethnicities as well [41]. One of the preferred methods is to use the canine index, which uses the mesiodistal size of the mandibular canine together with intercanine width [42-44]. But the most widely used method is the mesiodistal and buccolingual dimensions [13, 22, 23]. The mandibular canine seems to have the greatest sex dimorphism among all teeth while incisors might have the least sexual dimorphism [24-26]. A recent meta-analysis suggested that the canine might have the most sex dimorphism among all teeth, which might be due to the longer duration of amelogenesis of this tooth in men compared to women [4]. This is in agreement with our findings of the possibility of the use of mandibular canines in predicting gender. Some researchers have shown that when the mesiodistal size of the canine tooth is larger than 7.0 to $7.2 \mathrm{~mm}$, there is a very high probability that the person is male $[16,24,45]$, and this was in line with our results pertaining to the mandibular canine. Some authors have suggested that both the mesiodistal and buccolingual dimensions are needed together for sex determination [46]. In our study, many molar teeth could be used for sex identification. In earlier research, this tooth was sometimes useful, and in some studies, it was useful merely alongside other teeth for sex determination, indicating the role of ethnicity in sex dimorphism [47-51].

Our findings indicated that aging might reduce the mesiodistal and buccolingual dimensions of certain teeth. In archaeological studies, the pattern of increased wear appears to be age-dependent, while in modern populations, men are more prone to tooth wear than women [35]. Such wear might affect both epidemiological and clinical outcomes and should be taken into account in such examinations.

The Bolton ratios found in this study were within the range reported earlier $[6,7,11,33,34]$. In comparison to the original Bolton ratios, our sample's anterior Bolton ratio was larger. This should be considered when practicing on Iranian patients; still, it should be noted that such results are not definitive, and sometimes, even studies conducted within the same ethnicity and country yield different results $[6,11]$. The Angle classes were not associated with the anterior and posterior Bolton ratios in this sample. This finding was similar to some previous studies [ $8,52-54]$ but in contrast to some others $[33,55]$. It was found, however, that the posterior Bolton ratio might be smaller in class II patients, compared to classes I and III. In terms of sex dimorphism in Bolton ratios, when our whole sample was assessed, no sexual dimorphism was observed in this study. This finding was in line with most previous studies as well as the conclusion of a recent meta-analysis on Bolton ratios $[6,7,53-55]$. However, when sex dimorphism was examined separately within each of the Angle classes I or II, it was found that in class II patients, the anterior Bolton ratio might be greater in men than in women. We observed a $70 \%$ positive correlation between the anterior and overall Bolton indices. This was greater than the studies of Bolton (50\% correlation) [10] or White (-12\% correlation) [56] but slightly smaller than a study on Sudanese people (79\% correlation) [7]. The controversies might be attributable to real ethnic differences as well as methodological variations such as eligibility criteria or sample sizes. The concept of the posterior Bolton ratio is introduced and assessed in merely two studies $[33,34]$. We observed a $74 \%$ correlation between the posterior and overall Bolton ratios and almost no correlation between the anterior and posterior Bolton ratios. More studies are needed on the posterior Bolton ratio.

This study was limited by some factors. The number of females was much greater than males, although both seemed to be adequate. Moreover, the sample size pertaining to the Bolton ratios of class III men was very small. Hence, we did not perform inferential statistics on this subgroup. The generalizability of some aspects of this research was limited to the target population (Iranian orthodontic patients).

\section{Conclusions}

Within the limitations of this study, the following key points can be summarized:

(1) Sex dimorphism existed in most dental measurements. ROC curve analyses indicated that $(A)$ the mandibular teeth mostly seemed better than the maxillary ones for sex identification; (B) the most appropriate dental measurements for sex determination were the buccolingual dimension of the right and left maxillary canines, the buccolingual measurement of the right and left mandibular canines and the right and left mandibular first premolars, 
as well as (C) the mesiodistal dimension of the right and left mandibular canines

(2) Cut-off points for sex identification based on proper dental measurements were calculated for 38 teeth. In the maxilla, the buccolingual cut-off points ranged from $7.715 \mathrm{~mm}$ for the central to $11.715 \mathrm{~mm}$ for the first molar; the mesiodistal cut-offs ranged from $8.750 \mathrm{~mm}$ for the central to $10.815 \mathrm{~mm}$ for the first molar. In the mandible, the range of buccolingual cut-off points was $6.175 \mathrm{~mm}$ to $11.455 \mathrm{~mm}$ (the central to the first molar), while the range of mesiodistal cut-off points was $6.835 \mathrm{~mm}$ to $10.910 \mathrm{~mm}$ (the canine to the first molar).

(3) (A) Aging might slightly reduce the buccolingual crown dimension in a few posterior teeth: the right and left maxillary first premolar and second premolar and right and left mandibular second premolar and first molar. (B) It might also slightly reduce the mesiodistal widths of certain anterior and posterior teeth: the right maxillary first premolar and first molar, the left maxillary central, canine, first premolar, first molar, the right mandibular lateral, first premolar, and first molar, and the left mandibular central, lateral, and first premolar

(4) (A) The only measurements differing among the skeletal Angle classes were the buccolingual widths of the maxillary lateral, the mandibular central, and the mandibular lateral. These differed mainly between classes I and II. (B) Dental measurements might not differ between crowded and noncrowded dentitions. (C) All crown sizes might be smaller in microdontia cases compared to cases without this anomaly

(5) The anterior, posterior, and overall Bolton indices were 78.05, 105.42, and 91.87, respectively. The skeletal Angle classification might not be associated with the anterior and overall Bolton ratios. However, class II patients might have smaller posterior Bolton ratios compared to class I or III patients. Aging might not affect Bolton indices. In the whole sample, there was no sexual dimorphism in either of these indices. However, in class II patients, the anterior Bolton ratio was greater in men than in women. There were $69.6 \%$ and $74.0 \%$ correlations between the overall Bolton indexes with the anterior and posterior Bolton indices, respectively. The anterior and posterior Bolton indices might not be correlated. The overall Bolton ratio in this population might not differ much from the original overall Bolton ratio. Nonetheless, this population's anterior Bolton ratio might be greater than Bolton's original anterior ratio

\section{Data Availability}

The raw data are available from the authors upon reasonable request.

\section{Ethical Approval}

Protocol ethics were approved by the Research Committee of the University in accordance with the Helsinki Declaration.

\section{Conflicts of Interest}

The authors declare that they have no conflict of interest.

\section{Authors' Contributions}

Negin Ashoori collected the data and wrote the thesis. Fataneh Ghorbanyjavadpour collected the data and mentored the thesis. Vahid Rakhshan conceived the study and all the ideas and hypotheses, designed the study, validated the data and fully analyzed it, mentored the thesis, interpreted the findings, drafted and revised the manuscript, and created the Tables/Appendix/Figures.

\section{Supplementary Materials}

Supplementary file: Appendix 1. Online supplementary spreadsheet showing partial correlation coefficients (controlling for the role of sex) across tooth sizes and between age and tooth sizes. (Supplementary Materials)

\section{References}

[1] V. Deepak, S. Goryawala, Y. Reddy, and R. Chhabra, "Assessment of ethnicity in Indian population using tooth crown metric dental traits," Journal of International Oral Health: $\mathrm{JIOH}$, vol. 7, no. 9, pp. 83-87, 2015.

[2] R. Togoo, W. Alqahtani, E. Abdullah et al., "Comparison of mesiodistal tooth width in individuals from three ethnic groups in southern Saudi Arabia," Nigerian Journal of Clinical Practice, vol. 22, no. 4, p. 553, 2019.

[3] A. I. Shaweesh, "Mesiodistal and faciolingual diameters of the permanent teeth in a Jordanian population," Archives of Oral Biology, vol. 73, pp. 253-258, 2017.

[4] P. R. da Silva, M. C. Lopes, I. E. Martins-Filho, M. G. H. Biazevic, and E. Michel-Crosato, "Tooth crown mesiodistal measurements for the determination of sexual dimorphism across a range of populations: a systematic review and metaanalysis," The Journal of Forensic Odonto-Stomatology, vol. 37, no. 1, pp. 2-19, 2019.

[5] M. K. Agenter, E. F. Harris, and R. N. Blair, "Influence of tooth crown size on malocclusion," American Journal of Orthodontics and Dentofacial Orthopedics, vol. 136, pp. 795-804, 2009.

[6] V. Machado, J. Botelho, P. Mascarenhas, J. J. Mendes, and A. Delgado, "A systematic review and meta-analysis on Bolton's ratios: normal occlusion and malocclusion," Journal of Orthodontics, vol. 47, pp. 7-29, 2020.

[7] A. H. AaH, A.-H. M. Eldin, and H. A. Hashim, "Bolton tooth size ratio among Sudanese population sample: a preliminary study," Journal of Orthodontic Science, vol. 4, no. 3, pp. 7782, 2015.

[8] D. R. Crosby and C. G. Alexander, "The occurrence of tooth size discrepancies among different malocclusion groups," American Journal of Orthodontics and Dentofacial Orthopedics, vol. 95, pp. 457-461, 1989. 
[9] J. E. Freeman, A. J. Maskeroni, and L. Lorton, "Frequency of Bolton tooth-size discrepancies among orthodontic patients," American Journal of Orthodontics and Dentofacial Orthopedics, vol. 110, pp. 24-27, 1996.

[10] W. A. Bolton, "Disharmony in tooth size and its relation to the analysis and treatment of malocclusion," The Angle Orthodontist, vol. 28, pp. 113-130, 1958.

[11] M. Kachoei, M. H. Ahangar-Atashi, and S. Pourkhamneh, "Bolton's intermaxillary tooth size ratios among Iranian schoolchildren," Medicina Oral, Patología Oral y Cirugía Bucal, vol. 16, pp. e568-e572, 2011.

[12] T. Brown, B. Margetts, and G. Townsend, "Comparison of mesiodistal crown diameters of the deciduous and permanent teeth in Australian Aboriginals," Australian Dental Journal, vol. 25, pp. 28-33, 1980.

[13] C. F. Moorrees, S. Ø. Thomsen, E. Jensen, and P. K.-J. Yen, "Mesiodistal crown diameters of the deciduous and permanent teeth in individuals," Journal of Dental Research, vol. 36, pp. 39-47, 1957.

[14] T. Yonezu, J. J. Warren, S. E. Bishara, and K. L. Steinbock, "Comparison of tooth size and dental arch widths in contemporary Japanese and American preschool children," World Journal of Orthodontics, vol. 2, 2001.

[15] H.-I. Yoo, D.-W. Yang, M.-Y. Lee, M.-S. Kim, and S.-H. Kim, "Morphological analysis of the occlusal surface of maxillary molars in Koreans," Archives of Oral Biology, vol. 67, pp. 1521, 2016.

[16] P. Srivastava, "Correlation of odontometric measures in sex determination," Journal of Indian Academy of Forensic Medicine, vol. 32, pp. 56-61, 2010.

[17] R. Thapar, P. V. Angadi, S. Hallikerimath, and A. D. Kale, "Sex assessment using odontometry and cranial anthropometry: evaluation in an Indian sample," Forensic Science, Medicine, and Pathology, vol. 8, pp. 94-100, 2012.

[18] S. A. Mackinejad, R. Kaviani, V. Rakhshan, and F. Khabir, "Assessment of the cut-off point of mesiodistal and buccolingual widths of permanent teeth for determination of sex," Isfahan Dental Journal, vol. 11, pp. 153-162, 2015.

[19] S. S. Babu, S. S. Nair, D. Gopakumar, N. Kurian, A. Parameswar, and T. K. Baby, "Linear odontometric analysis of permanent dentition as a forensic aid: a retrospective study," Journal of Clinical and Diagnostic Research: JCDR, vol. 10, p. ZC24, 2016.

[20] A. Brook, R. Griffin, G. Townsend, Y. Levisianos, J. Russell, and R. Smith, "Variability and patterning in permanent tooth size of four human ethnic groups," Archives of Oral Biology, vol. 54, pp. S79-S85, 2009.

[21] F. Hattab, S. Al-Khateeb, and I. Sultan, "Mesiodistal crown diameters of permanent teeth in Jordanians," Archives of Oral Biology, vol. 41, pp. 641-645, 1996.

[22] S. Garn, A. Lewis, and A. Walenga, "Maximum-confidence values for the human mesiodistal crown dimension of human teeth," Archives of Oral Biology, vol. 13, pp. 841-844, 1968.

[23] S. M. Garn, P. Cole, R. Wainwright, and K. Guire, "Sex discriminatory effectiveness using combinations of permanent teeth," Journal of Dental Research, vol. 56, no. 6, pp. 697697, 1977.

[24] S. Kaushal, V. Patnaik, and G. Agnihotri, "Mandibular canines in sex determination," Journal of the Anatomical Society of India, vol. 52, pp. 119-124, 2003.
[25] S. M. Garn, A. B. Lewis, D. R. Swindler, and R. S. Kerewsky, "Genetic control of sexual dimorphism in tooth size," Journal of Dental Research, vol. 46, pp. 963-972, 1967.

[26] J. W. Hsu, P. L. Tsai, T. H. Hsiao, H. P. Chang, L. M. Liu, K. M. Liu et al., "Ethnic dental analysis of shovel and Carabelli's traits in a Chinese population," Australian Dental Journal, vol. 44, pp. 40-45, 1999.

[27] D. L. Anderson and G. W. Thompson, "Interrelationships and sex differences of dental and skeletal measurements," Journal of Dental Research, vol. 52, pp. 431-438, 1973.

[28] K. Petersen and S. Kogon, "Dental identification in the Woodbridge disaster," Journal of the Canadian Dental Association, vol. 37, pp. 275-279, 1971.

[29] N. H. Felemban and B. S. Manjunatha, "Prevalence of the number of cusps and occlusal groove patterns of the mandibular molars in a Saudi Arabian population," Journal of Forensic and Legal Medicine, vol. 49, pp. 54-58, 2017.

[30] T. K. Baby, S. Sunil, and S. S. Babu, "Nonmetric traits of permanent posterior teeth in Kerala population: a forensic overview," Journal of oral and maxillofacial pathology: JOMFP, vol. 21, p. 301, 2017.

[31] F. Ghorbanijavadpour, V. Rakhshan, and N. Ashoori, "Evaluation of prevalence of hypodontia based on sex, dental and skeletal relationship in patients admitted to Ahvaz Dental School," Journal of Isfahan Dental School, vol. 17, pp. 56-63, 2021.

[32] R. C. Scheid and G. Weiss, Woelfel's dental anatomy, Jones \& Bartlett Publishers, 2020.

[33] H. R. Fattahi, H. R. Pakshir, and Z. Hedayati, "Comparison of tooth size discrepancies among different malocclusion groups," European Journal of Orthodontics, vol. 28, pp. 491495, 2006.

[34] A. Laino, G. Quaremba, S. Paduano, and S. Stanzione, "Prevalence of tooth-size discrepancy among different malocclusion groups," Progress in Orthodontics, vol. 4, pp. 37-44, 2003.

[35] A. Brook, C. Underhill, L. Foo, and M. Hector, "Approximal attrition and permanent tooth crown size in a RomanoBritish population,” Dental Anthropology Journal, vol. 19, pp. 23-28, 2006.

[36] S. E. Bishara, J. R. Jakobsen, E. M. Abdallah, and A. F. Garcia, "Comparisons of mesiodistal and bnccolingnal crown dimensions of the permanent teeth in three populations from Egypt, Mexico, and the United States," American Journal of Orthodontics and Dentofacial Orthopedics, vol. 96, pp. 416-422, 1989.

[37] H. Bailit, "Dental variation among populations. An anthropologic view," Dental Clinics of North America, vol. 19, pp. 125139, 1975.

[38] A. Brook, "A unifying aetiological explanation for anomalies of human tooth number and size," Archives of Oral Biology, vol. 29, pp. 373-378, 1984.

[39] T. Hanihara and H. Ishida, "Metric dental variation of major human populations," American Journal of Physical Anthropology: The Official Publication of the American Association of Physical Anthropologists, vol. 128, pp. 287-298, 2005.

[40] J. A. Kieser and K. Julius, Human Adult Odontometrics: the Study of Variation in Adult Tooth Size, Cambridge University Press, 1990.

[41] J. Verhoeven, J. Van Aken, and G. Van Der Weerdt, "The length of teeth: a statistical analysis of the differences in length 
of human teeth for radiologic purposes," Oral Surgery, Oral Medicine, Oral Pathology, vol. 47, pp. 193-199, 1979.

[42] N. G. Rao, N. N. Rao, M. L. Pai, and M. S. Kotian, "Mandibular canine index-a clue for establishing sex identity," Forensic Science International, vol. 42, pp. 249-254, 1989.

[43] H. Sherfudhin, M. Abdullah, and N. Khan, "A cross-sectional study of canine dimorphism in establishing sex identity: comparison of two statistical methods," Journal of Oral Rehabilitation, vol. 23, pp. 627-631, 1996.

[44] M. Muller, L. Lupi-Pegurier, G. Quatrehomme, and M. Bolla, "Odontometrical method useful in determining gender and dental alignment," Forensic Science International, vol. 121, pp. 194-197, 2001.

[45] B. Rai, S. Dhattarwal, S. Anand, and D. Bhardwaj, "Mesio-distal diameter of mandibular canine as a sex and intercanine distance as the age determinant," Indian Internet Journal of Forensic Medicine \& Toxicology, vol. 6, pp. 44-47, 2008.

[46] A. B. Acharya and S. Mainali, "Sex discrimination potential of buccolingual and mesiodistal tooth dimensions," Journal of Forensic Sciences, vol. 53, pp. 790-792, 2008.

[47] R. Shrestha, "Measurement of mesio-distal tooth diameter of Nepalese permanent dentition," Journal of Nepal Dental Association, vol. 7, pp. 55-63, 2005.

[48] M. Y. İşcan and P. S. Kedici, "Sexual variation in bucco-lingual dimensions in Turkish dentition," Forensic Science International, vol. 137, pp. 160-164, 2003.

[49] G. Townsend, "Tooth size characteristics of Australian Aborigines," Occasional Papers in Human Biology, vol. 1, pp. 17-38, 1979.

[50] L. J. Ghose and V. S. Baghdady, "Analysis of the Iraqi dentition: mesiodistal crown diameters of permanent teeth," Journal of Dental Research, vol. 58, pp. 1047-1054, 1979.

[51] E. F. Harris and M. T. Nweeia, "Tooth size of Ticuna Indians, Colombia, with phenetic comparisons to other Amerindian," American Journal of Physical Anthropology, vol. 53, pp. 8191, 1980.

[52] H. A. Hashim and B. Zuhair Murshid, "Mesiodistal tooth width in a Saudi population: a preliminary report," Saudi Dental Journal, vol. 5, pp. 68-72, 1992.

[53] G. Basaran, M. Selek, O. Hamamci, and Z. Akkuş, "Intermaxillary Bolton tooth size discrepancies among different malocclusion groups," The Angle Orthodontist, vol. 76, pp. 26-30, 2006.

[54] T. Uysal, Z. Sari, F. A. Basciftci, and B. Memili, "Intermaxillary tooth size discrepancy and malocclusion: is there a relation?," The Angle Orthodontist, vol. 75, pp. 208-213, 2005.

[55] Q. Nie and J. Lin, "Comparison of intermaxillary tooth size discrepancies among different malocclusion groups," American Journal of Orthodontics and Dentofacial Orthopedics, vol. 116, pp. 539-544, 1999.

[56] L. W. White, "The clinical use of occlusograms," Journal of Clinical Orthodontics, vol. 16, pp. 92-103, 1982. 